\title{
Tropical cyclones in climate models
}

\author{
Suzana J. Camargo* and Allison A. Wing
}

Edited by Eduardo Zorita, Domain Editor, and Mike Hulme, Editor-in-Chief

In this review, we provide a historical overview of the simulation of tropical cyclones (TCs) in climate models, from the first attempts in the 1970s to the current state-of-the-art models. We discuss the status of TC simulation across multiple time scales, from intraseasonal, seasonal, and decadal, to climate change. One of the limitations on the simulation of TCs in climate models has been, and continues to be, balancing the high resolution necessary to accurately simulate TCs themselves with the need to run simulations for many years and using many ensemble members. Several approaches to inferring TC activity indirectly, rather than relying on the models own under-resolved TCs, are reviewed, including the use of TC genesis indices based on the large-scale environment and downscaling methods such as the use of regional climate models and statistical-dynamical techniques. We also provide an update on the status of climate change projections from the current class of models, where it is feasible to directly track the model's TCs. While there has been great progress in the capability of climate models to simulate TCs and provide useful forecasts and projections across multiple time scales, there remains much work to be done. We list some of the sources of uncertainty and model sensitivity, describe where improvements are necessary, and provide a few suggestions for promising research directions. (C) 2015 Wiley Periodicals, Inc.

How to cite this article:
WIREs Clim Change 2016, 7:211-237. doi: $10.1002 /$ wcc.373

\section{INTRODUCTION}

$\mathrm{H}$ urricanes and typhoons [or more generally, tropical cyclones (TCs)] are one of the most destructive natural phenomena on Earth and are responsible for great social and economic losses. Because of the potentially devastating impacts of a TC landfall, the question of how these storms will be affected by climate change is of vital importance. One of the challenges in studying the effect of climate change on TCs is that the models typically used in climate change simulations have low horizontal resolution, so that it is computationally feasible to

*Correspondence to: suzana@ldeo.columbia.edu

Lamont-Doherty Earth Observatory, Columbia University, Palisades, NY, USA

Conflict of interest: The authors have declared no conflicts of interest for this article. perform long simulations with multiple ensemble members and various future scenarios. However, in order to accurately simulate TCs, it is necessary to run models at much higher resolutions. This conflict has made the study of TCs in climate models a difficult task, and also one that has received considerable attention over the last several decades.

Since the 1970s, it has been known that even low-resolution climate models are able to produce vortices with characteristics similar to those of TCs., ${ }^{1,2}$ The earlier studies of the relationship between climate change and $\mathrm{TCs}^{3-5}$ used these lowresolution climate models, in spite of the weak intensity of the modeled storms and model biases. In recent years, the exponential improvement in computational capacity has enabled various modeling groups to employ high-resolution climate models, which has led to a dramatic improvement in our ability to simulate TCs, in the short term (intraseasonal 
variability), medium term (dynamical seasonal forecasting), and long term (climate change projections).

In this review, we will give a historical perspective on the simulation of TCs in climate models; Earlier Studies of TCs in Climate Models describes the first studies in the 1970s and 1980s while Progress in the 1990s discusses progress made in the 1990s. Approaches to inferring TC activity in climate models by analyzing the large-scale environmental conditions are reviewed in Large-scale Environment and TCs. In Regional Climate Models, Downscaling and TCs, we describe methods of downscaling TC activity from climate models. In TC Dynamical Seasonal Forecasts, we discuss the advent of TC dynamical seasonal forecasting. We next describe the simulation of TCs in the current state-of-the-art global climate models, including the simulation of intraseasonal and decadal time scales (Current State-of-the-art Global Climate Models: From Intraseasonal to Decadal Time Scales) as well as climate change (Current State-of-the-art Global Climate Models: Climate Change Projections). Finally, we provide an overview of model sensitivities and limitations in Model Sensitivities before suggesting possible ways of improving the simulation of TCs in climate models and directions for future research in the Conclusion.

\section{EARLY STUDIES OF TCs IN CLIMATE MODELS}

The study of the TCs in climate models dates back to Manabe et al., ${ }^{1}$ who analyzed the characteristics of the tropical circulation in a global atmospheric circulation model. They noted the occurrence of cyclonic vortices in regions in which TCs form in observations (Figure 1). The vortices were accompanied by low surface pressure values, heavy precipitation, and strong convergence of air near the surface and divergence in the upper troposphere. The movement of these vortices was also compatible with observed TCs (Figure 1). Although the structure of the vortices was somewhat similar to observed storms, it was clear that the model was unable to sufficiently resolve the vortices, and therefore, could not intensify the storms to tropical storm strength. Nevertheless, the processes occurring in the vortices, such as the development of a warm core with a deepening of the surface pressure and latent and sensible heat fluxes from the ocean surface to the atmosphere in the region of the storm, had strong similarities to what was known about TCs at that time.

A pioneering study on TCs in global models was that of Bengtsson et al., ${ }^{2}$ who analyzed

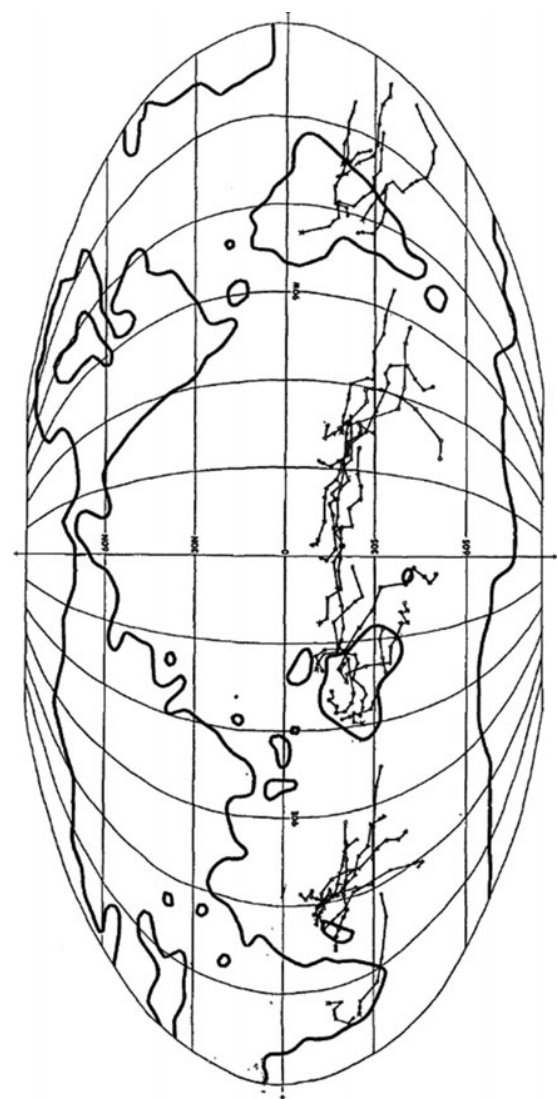

FIGURE 1 | Tracks of tropical cyclones from the points of origin (indicated by an $\mathrm{x}$ ). Symbols indicate positions at 1-day intervals. The simulation is forced with February SSTs. The storms were identified in the 40-day period of the simulation. (Reprinted with permission from Ref 1. Copyright 1970 American Meteorological Society)

hurricane-type vortices in a 1-year simulation of the European Centre for Medium-Range Weather Forecasts (ECMWF) operational global model with a horizontal resolution of $1.875^{\circ}$. The spatial and temporal pattern of occurrence of these vortices was similar to that of observed TCs; in particular, there was a clear maximum in TC activity over the western North Pacific. Other characteristics, such as lifetime and structure, also fundamentally agreed with the characteristics of observed storms. Bengtsson et al. ${ }^{2}$ also discussed the sensitivity of the vortices to the model environment; in particular, sea surface temperature (SST). They found that formation occurred only for SSTs above $28-29^{\circ} \mathrm{C}$ and under conditions of large-scale divergence in the upper troposphere; these conditions are broadly consistent with those favorable for TC formation in nature, although TC formation is observed at lower values of $\operatorname{SST}\left(\sim 26^{\circ} \mathrm{C}\right)$.

In the mid to late 1980 s, significant progress was achieved in the forecasting of individual TCs, ${ }^{6-8}$ 
which led to a better understanding of the model characteristics that are necessary for simulating TCs. Krishnamurti et al. ${ }^{9}$ showed that the formation and motion of storms is improved when the model has a high horizontal resolution, adequate resolution of surface layer fluxes, and includes parameterizations of boundary layer, cumulus convection, and radiative processes. Many global models have already included these parameterizations and processes, leading to improved simulations of TC climatology in global models. Krishnamurti and Oosterhof ${ }^{10}$ showed that, with the use of a high-resolution model and a sophisticated data assimilation scheme, it was possible to obtain a good forecast of a typhoon lifetime, from tropical depression stage to landfall. This was a very significant result at the time, which greatly influenced future work on TCs in global models.

\section{PROGRESS IN THE 1990s}

The idea of using global climate models to examine the influence of climate change on TCs was first proposed by Broccoli and Manabe. ${ }^{3}$ In this study, control simulations of the current climate in the GFDL (Geophysical Fluid Dynamics Laboratory) climate model were compared with those in which the $\mathrm{CO}_{2}$ concentration was doubled. TC-like vortices were identified in both cases, using two different model horizontal resolutions, as well as different cloud treatments (prescribed cloudiness or allowing for cloud feedbacks). With prescribed cloudiness, $\mathrm{CO}_{2}$ doubling led to a large increase in the number of storm days, while there was a small reduction in the number of storm days in simulations that allowed for cloud feedbacks. Though the results of this study were inconclusive, it launched a new way of studying the influence of climate change on TCs that is still used today.

The modulation of TC activity by the El NiñoSouthern Oscillation (ENSO) phenomenon was the next topic explored using global climate models in the early 1990s. The relationship between TCs and ENSO has been well known in observations since the pioneering papers of Neville Nicholls, for the Australian region, ${ }^{11-13}$ and William Gray, ${ }^{14}$ for the North Atlantic. Wu and $\mathrm{Lau}^{15}$ were the first to explore whether global climate models were able to reproduce the changes in TC frequency in different basins due to ENSO. They forced the GFDL climate model with observed monthly varying SSTs for 15 years and analyzed how the TC frequency changed in El Niño and La Niña events. Most importantly, they were able to use the differences in the model environmental fields between the cold and warm phases of ENSO to determine how the modulation of TC activity in the different basins occurred. The modulation of TC activity by large-scale climatic variability remains an area of active research and has led to the development of dynamical TC seasonal forecasts, which will be discussed below in more detail.

As computing capability increased in the 1990 s and it became possible to run global climate models at higher resolutions for many years, there was an increase in the number of studies analyzing the characteristics of TCs in different global climate models. Broccoli and Manabe ${ }^{16}$ were able to produce a moderately successful simulation of a TC climatological occurrence distribution. Bengtsson et al. ${ }^{17}$ considered the simulation of TCs in two versions of the same model with different horizontal resolutions (T42 or $\sim 300 \mathrm{~km}$ and T106 or $\sim 150 \mathrm{~km}$ ), forced with climatological monthly SSTs. They showed that there are considerable variations in TC frequency from year to year, even without interannual variations in the SSTs. Furthermore, they showed that the intensity and structure of the storms were resolution dependent, with low-resolution simulations producing weaker and larger storms with a less realistic vertical and horizontal structure (Figure 2).

Using a model with a lower resolution (T42 or $\sim 300 \mathrm{~km}$ ), Tsutsui and Kasahara ${ }^{18}$ analyzed the differences in TC frequency in the NCAR CCM2 (National Center for Atmospheric Research Community Climate Model 2) model forced with climatological SSTs or with interannually varying SSTs. They found that the simulation forced with climatological SSTs produced a significantly larger annual frequency of TC-like vortices. Despite this bias in the average frequency, in regions such as the Atlantic where interannual variability in observed TC frequency is large, the model forced with observed, interannually varying SSTs was able to reproduce these fluctuations. This was another important step toward the development of dynamical seasonal TC forecasts.

The potential for using climate models for dynamical TC seasonal forecasts was further explored by Vitart et al., ${ }^{19}$ who, using a nine-member ensemble, performed a 10 -year integration of a climate model forced with observed SSTs. The ensemble members differed only in the initial conditions of the atmosphere. They showed that the predictability of the frequency of TCs in this model was particularly strong in the western and eastern North Pacific, as well as in the North Atlantic. In these regions, the simulation skill was exceptionally high, particularly in years of strong ENSO signals. A follow-up study ${ }^{20}$ 

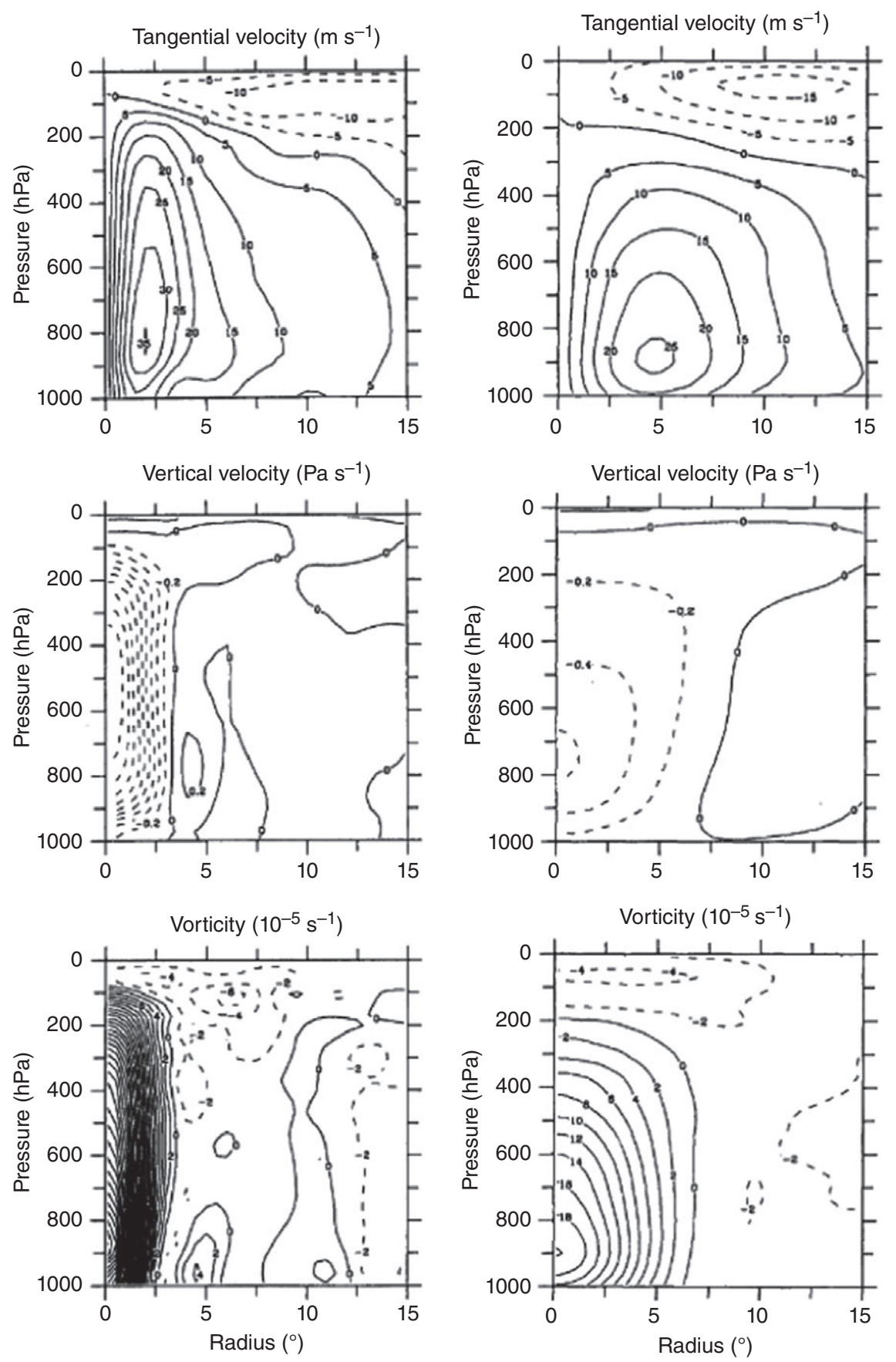

FIG URE 2 | Two-dimensional cross section of tangential wind $\left(\mathrm{m} \mathrm{s}^{-1}\right)$, vertical velocity $\left(\mathrm{Pa} \mathrm{s}^{-1}\right)$, and vorticity $\left(10^{-5} \mathrm{~s}^{-1}\right)$ for the maximum stage of the development of a tropical cyclone in ECHAM3 with resolution T106 (left panel) and T42 (right panel). (Adapted from Ref 17 with permission. Made available under the terms of the Creative Commons Attribution 4.0 International (CC_BY) License)

showed that predictability also exists for TC intensity and location of formation, in addition to TC frequency. This modeling study also showed that in some regions, TC frequency was not significantly correlated to the local SST, which suggested that the remote impact of other regions, communicated by the large-scale circulation, was important for the TC-
ENSO modulation. This is similar to what occurs in observations. This result was particularly encouraging, as in general there is more confidence in the large-scale environmental conditions generated by global climate models than in the storms themselves.

As confidence in the ability of climate models to simulate TCs increased in the 1990s, two papers 
analyzed the impact of climate change on the simulated TC activity. Haarsma et al. ${ }^{4}$ used an atmospheric model coupled to a mixed layer ocean in two scenarios: a control case and a simulation in which the $\mathrm{CO}_{2}$ concentration was doubled. In the doubled $\mathrm{CO}_{2}$ scenario, the number of tropical disturbances increased by $50 \%$ compared with the control (Figure 3). Furthermore, there was a relative increase in the number of intense storms, whose intensity increased $\sim 20 \%$ (Figure 3). A different approach was used by Bengtsson et al., ${ }^{5}$ who forced a highresolution atmospheric model with fixed SST. For the doubled $\mathrm{CO}_{2}$ scenario, anomalies were added to the monthly SST climatology, which were generated by a low-resolution coupled atmosphere-ocean model. In that case, the frequency of TCs was reduced in the doubled $\mathrm{CO}_{2}$ scenario, especially in the southern hemisphere, while the intensity of the most intense storms increased. The increase in intensity and in the frequency of intense storms obtained in both papers agrees with the theoretical estimates by Emanuel. ${ }^{21,22}$ A decrease in overall TC frequency and a higher occurrence of intense storms remain robust responses to increased $\mathrm{CO}_{2}$ in the current state-of-the art models. ${ }^{23}$

\section{LARGE-SCALE ENVIRONMENT AND TCs}

Although the TC-like vortices detected and tracked in low-resolution climate models have many characteristics similar to observed TCs, until recently most models had large biases in reproducing the observed TC frequency, intensity, and geographical distribution (e.g., Vitart et al. ${ }^{19}$ and Camargo et al. $\left.^{24}\right)$. Therefore, many authors have used an alternative method of studying TC activity in climate models-instead of studying the model disturbances per se, they focused on large-scale environment conditions that are associated with TC activity. One common way to analyze the environmental conditions associated with TC frequency in models is to use genesis potential indices. An example of the correspondence between one particular genesis index and observed TC genesis points is shown in Figure 4.

Gray $^{26}$ developed the first genesis index as a function of several environmental parameters: lowlevel $(950 \mathrm{hPa})$ vorticity, vertical wind shear (between 950 and $200 \mathrm{hPa}$ ), the Coriolis parameter, ocean thermal energy (the temperature excess above $26^{\circ} \mathrm{C}$ integrated from the ocean surface down to the $60 \mathrm{~m}$ depth), moist static stability (the vertical gradient of the equivalent potential temperature between the surface and $500 \mathrm{hPa}$ ), and average relative humidity (between 500 and $700 \mathrm{hPa}$ ). However, his index is not appropriate to explore TC activity in climate change scenarios, as it uses a fixed SST threshold. After the introduction of this first genesis index, many others have appeared in the literature which use different environmental variables or different functional dependences of the indices on the environmental variables. One of the most commonly used

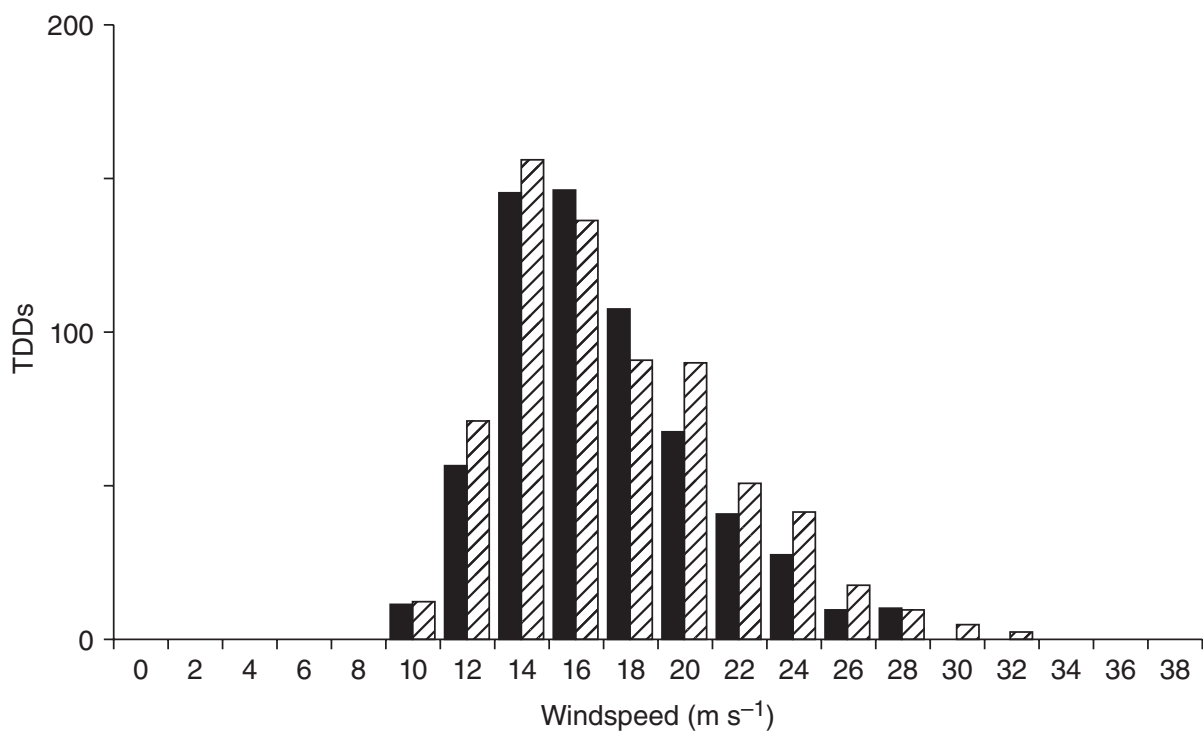

FIGURE 3 | Frequency distribution of windspeed for 10 years of NW Pacific storms. Solid columns: control simulation. Cross-hatched columns: on doubling $\mathrm{CO}_{2}$. (Reprinted with permission from Ref 4. Copyright 1993 Springer Science and Business Media) 

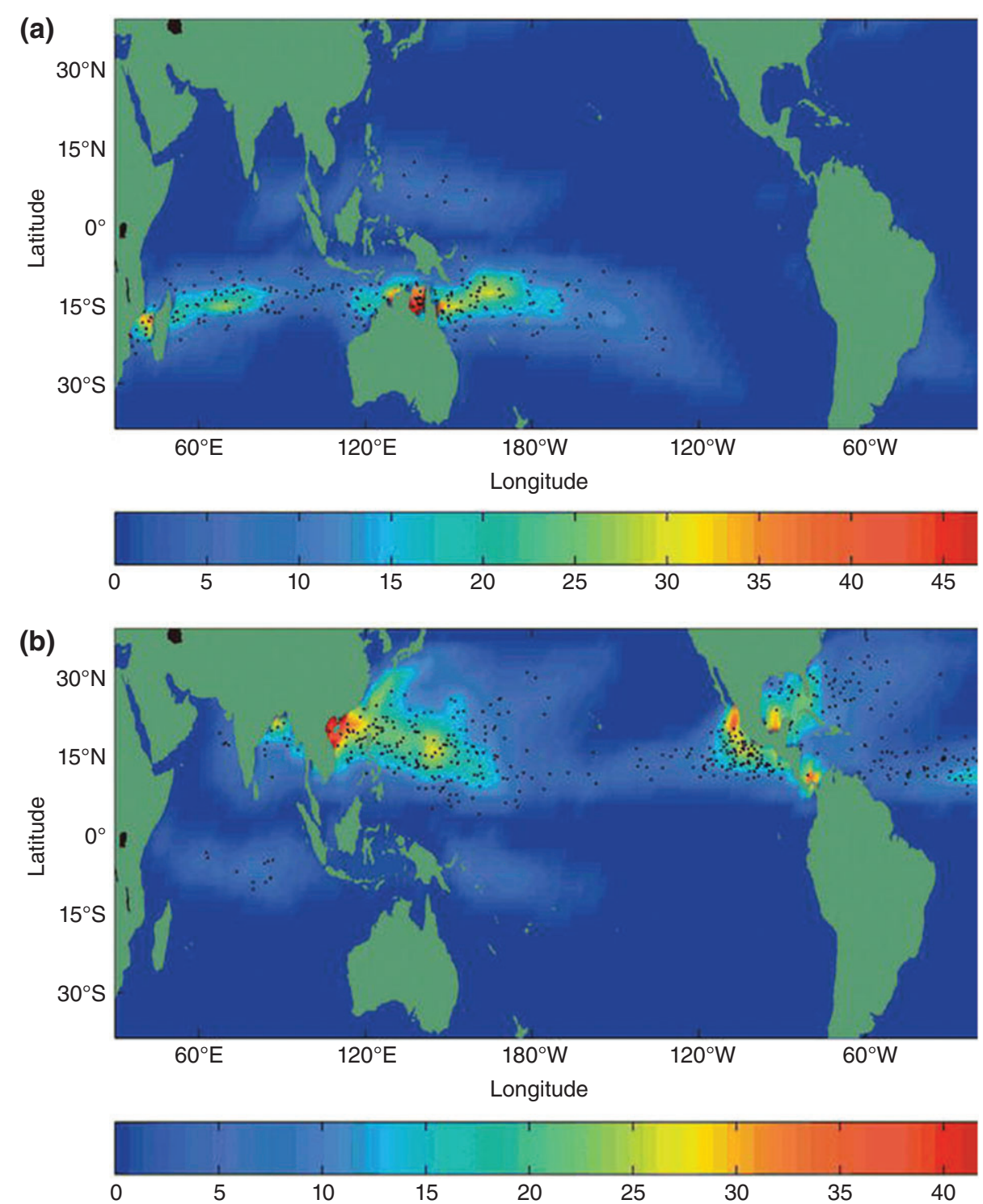

FIGURE 4 | Genesis potential index climatology in (a) February and (b) September. The black dots show individual genesis events over the period from (a) 1970-2004 and (b) 1970-2005. (Reprinted with permission from Ref 25. Copyright 2007 American Meteorological Society)

genesis indices is the Emanuel and Nolan genesis potential index (GPI), ${ }^{27}$ in which the potential intensity $^{28,29}$ replaces SST. The definition of Emanuel and Nolan's GPI is:

$$
\mathrm{GPI}=\left|10^{5} \eta\right|^{3 / 2}\left(\frac{H}{50}\right)^{3}\left(\frac{V_{\text {pot }}}{70}\right)^{3}\left(1+0.1 \mathrm{~V}_{\text {shear }}\right)^{-2}
$$

where $\eta$ is the absolute vorticity at $850 \mathrm{hPa}, H$ is the relative humidity at $600 \mathrm{hPa}, V_{\text {pot }}$ is the potential intensity, and $V_{\text {shear }}$ is the magnitude of the vertical wind shear between 850 and $200 \mathrm{hPa}$. Many other genesis indices have been developed since, e.g., Emanuel, ${ }^{30}$ Tippett et al., ${ }^{31}$ and Bruyère et al. $^{32} \mathrm{~A}$ recent comparison of the performance of genesis indices in the present climate is given in Menkes et al. ${ }^{33}$ As examples of the different functional forms used in genesis indices, we show here Emanuel's new genesis index ${ }^{30}$ :

$$
\text { GPI }^{*}=|\eta|^{3} \chi^{-4 / 3} \max \left(\left(V_{\text {pot }}-35\right), 0\right)^{2}\left(25+V_{\text {shear }}\right)^{-4}
$$

where $\chi$ is a non-dimensional parameter that is a measure of the moist entropy deficit of the middle troposphere; and Tippett et al.'s ${ }^{31}$ index:

$$
\begin{aligned}
\mathrm{TCGI}= & \exp \left(\mathrm{b}+\mathrm{b}_{\eta} \min \left([\eta] \times 10^{5}, 3.7\right)\right. \\
& \left.+\mathrm{b}_{\mathrm{H}} \mathrm{H}+\mathrm{b}_{\mathrm{PI}} \mathrm{V}_{\text {pot }}+\mathrm{b}_{\mathrm{V}} \mathrm{V}_{\text {shear }}\right),
\end{aligned}
$$


where the parameters $b$ are the coefficients of the Poisson regression between the climatological number of genesis events and the large-scale environmental variables.

The first application of genesis indices to climate models was done by Ryan et al., ${ }^{34}$ who used Gray's genesis index in the present climate and in a doubled $\mathrm{CO}_{2}$ simulation. In the doubled $\mathrm{CO}_{2}$ scenario, a significant increase in the region of tropical cyclogenesis was obtained, due to the linear relationship of the index with SST. Gray's genesis index was then applied to the same model ${ }^{35}$ to examine the differences of the environment during warm and cold ENSO years.

However, as shown in Camargo et al., ${ }^{36}$ in most models and basins, there is only a weak relationship between the frequency of model TCs and the mean values of the genesis index in each basin. Furthermore, there is a stronger relationship between the model genesis index and the observed TC variability than with the model TC variability, since the models have better skill at simulating the environmental fields than simulating the TCs themselves. McDonald et al., ${ }^{37}$ Camargo et al. ${ }^{36}$ and Walsh et al. ${ }^{38}$ indicated that as model horizontal resolution increases, there is more consistency between genesis indices and the mean model TC frequency. The large variations in model TC climatology that exist between models suggest that the model TC occurrence is more strongly controlled by the dynamics of the model storms than by the model environment for genesis. This is still the case in the current class of models, where there is a wide range of mean global TC frequency among the models despite the fact that the values and spatial distribution of the Emanuel and Nolan genesis index are very similar. ${ }^{39}$ Some authors $^{32,40}$ argue that to obtain a good relationship between regional TC activity and a regional genesis index it is necessary to develop regional genesis indices, or incorporate higher frequency variability instead of using global indices based on monthly climatology. While genesis can be initiated by different convective disturbance types, (such as equatorial waves, easterly waves, and monsoon lows), and these convective disturbances are basin dependent, the relationship between TC genesis and the large-scale environment does not necessarily have such a regional dependency. Therefore, as this is the relationship that genesis indices attempt to replicate, a globally derived genesis index seems to be the optimal choice.

Genesis indices continue to be widely applied to study the effect of climate change on TC activity. ${ }^{37,39,41,42}$ However, while high-resolution climate models robustly project a global decrease in TC activity under warmer conditions, most genesis indices project an increase in TC frequency. The projected decrease in TC frequency has been associated with an increase in the saturation deficit of the free troposphere with warming. Therefore, genesis indices that include the saturation deficit (such as Emanuel's new $\mathrm{GPI}^{30}$ ) should be able to reproduce this frequency reduction. However, as shown by Emanuel, ${ }^{43}$ even this new GPI projects an increase in TC frequency in a warming climate. An argument could be made that the genesis indices, which are based on the models large-scale environment, are correct. However, the projection of a global decrease in TC frequency is so robust among models that there would need to be a fundamental problem with climate models for that to be the case. Furthermore, there is no guarantee that the specific combination of environmental factors in a genesis index derived for the current climate is valid for other climates. Recently, Camargo et $\mathrm{al}^{4}{ }^{44}$ showed that only genesis indices that used a specific combination of environmental parameters (in particular, saturation deficit and potential intensity), are able to project the decrease in global TC frequency in a warmer climate, at least in the case of one global climate model. This hypothesis still needs to be tested in a wider range of models.

Another application of genesis indices is to analyze the level of TC activity in different past climates. While paleotempestology is a growing field, it is still in its infancy and the amount of data available to reconstruct storm activity in past climates is quite restricted. ${ }^{45,46}$ Paleoclimatology studies usually involve very long simulations, therefore computational constraints lead to use of low-resolution models. Genesis indices can then be used to compare the environmental conditions for TC formation in past (e.g., Last Glacial Maximum) and present climates and obtain estimates of the level of TC activity. This approach was used by Korty et al. for the Last Glacial Maximum ${ }^{47}$ and the mid-Holocene, ${ }^{48}$ with the caveat that genesis indices obtained for the current climate do not necessarily work for past climates. Therefore, Korty et al. also examined the changes in the individual environmental factors that compose the genesis index.

One of the ways that the environment influences TC genesis and intensity is through ventilation, the import of cool and dry air into the core of TCs by vertical wind shear, which is quantified by the new ventilation index of Tang and Emanuel. ${ }^{49,50}$ This ventilation index is a combination of environmental vertical shear, entropy deficit, and potential intensity, and has many applications, from real-time forecasting to climate change projections. The 
ventilation index can be used as a tool to examine changes in the environmental conditions due to climate change, which are relevant to TC activity in global climate models, as was done by Tang and Camargo. ${ }^{51}$ They showed that in the CMIP5 (Coupled Model Intercomparison Project Phase 5) dataset, there is a general tendency for an increase in the seasonal ventilation index in the majority of the TC basins. All models project an increase in the midlevel entropy deficit in the tropics, which is compensated by an increase in the potential intensity and a decrease in vertical wind shear in most basins.

As mentioned earlier, potential intensity is an important parameter in several genesis indices. The potential intensity is the theoretical maximum intensity that a TC can reach under specific environmental conditions. $^{22}$ The potential intensity also is closely related to the observed TC intensity. ${ }^{52,53}$ Recently, it has been used as a proxy to examine potential changes in TC intensity under climate change conditions in climate models. ${ }^{39,54}$ Vecchi and Soden ${ }^{54}$ showed that long-term changes in the potential intensity are closely related to the regional structure of SST warming in future projections, in which regions that warm more than the tropical average are characterized by an increase in potential intensity. Therefore, although overall there is a tendency for an increase of potential intensity in the tropics, there are some regions in which the potential intensity could decrease. The pattern of potential intensity change projected by the CMIP5 multi-model mean ${ }^{39}$ is extremely similar to that of the Vecchi and Soden analysis, which was obtained with CMIP3 (Coupled Model Intercomparison Project Phase 3). The potential intensity has also been used to separate the role of natural and anthropogenic environmental changes on North Atlantic TC intensity; ${ }^{55,56}$ the late 20th Century potential intensity trend in the North Atlantic was found to be dominated by internal variability and only at the end of the 21st century an anthropogenic potential intensity trend is expected to emerge. More recently, Polvani et al. used potential intensity to examine the potential impact of ozone on TC intensity $^{57}$ and found that the ozone depletion in recent decades has not been a major player in determining the TC intensity trends, and neither will ozone recovery in the first half of the 21 st century.

\section{REGIONAL CLIMATE MODELS, DOWNSCALING AND TCs}

Given the high computational costs required to run long, high-resolution climate model simulations that can simulate TCs with hurricane-strength intensity, various alternative strategies have been used. One strategy is to select storms from long climate model simulations and redo the simulation of those storms using higher resolution, operational hurricane forecast models in order to achieve more realistic intensities. $^{58,59}$ Another possibility is to perform simulations of individual idealized TCs in a simplified large-scale environment. ${ }^{59-61}$ These types of simulations were particularly successful in simulating the increase in TC intensity under global warming conditions and also other changes such as increased TC precipitation rates with climate warming. ${ }^{62}$ The advantage of this method is that these idealized simulations are usually cheap to run, which makes it possible to test the sensitivity of the results to various model choices, including environmental conditions of the forcing climate model, model parameterizations, and the use of fixed SST or a coupled ocean model. ${ }^{63}$

A powerful approach that has been used by various modeling groups is the use of regional climate models, forced at their boundaries by environmental conditions from global models. It is well known that the domain choice has an impact on the climate characteristics of regional climate models. ${ }^{64}$ This is also the case for simulation of TCs in regional models, as many TCs are advected through the model boundaries. Both grid point and spectral regional climate models ${ }^{65,66}$ have this sensitivity to the boundary condition. Caron and Jones ${ }^{67}$ showed that in the case of the Atlantic, it is crucial that the regional climate model domain include not only the tropical Atlantic, but a large part of northern Africa as well, due to the presence of African easterly waves and their relationship with Atlantic hurricane genesis. The use of regional climate models for TC dynamical seasonal forecasts has been tested and there are indications this type of downscaling can improve the forecast skill of global models in predicting TC landfall in East Asia, ${ }^{68}$ for example.

Regional climate models have been very successful in reproducing the hurricane activity in the North Atlantic in the late 20th century. ${ }^{69}$ In recent years, regional climate models were used to analyze the changes in TC frequency and intensity in the North Atlantic and western North Pacific under 21st century warming conditions. ${ }^{70-73}$ Figure 5 shows an example for the North Atlantic, where there was strong agreement between seasonal TC frequency in observations and in the model ensemble, although the intensity distribution lacked the strongest storms. As even a regional climate model with $18 \mathrm{~km}$ resolution is unable to simulate TCs with intensities of Category 4 and 5 on the Saffir-Simpson Hurricane 
(a) Atlantic Hurricanes (1980-2006): Simulated vs. Observed

Correlation $=0.84$; Linear trends: +0.21 storms year $^{-1}\left(\right.$ model) and +0.15 storms year $^{-1}$ (observed).
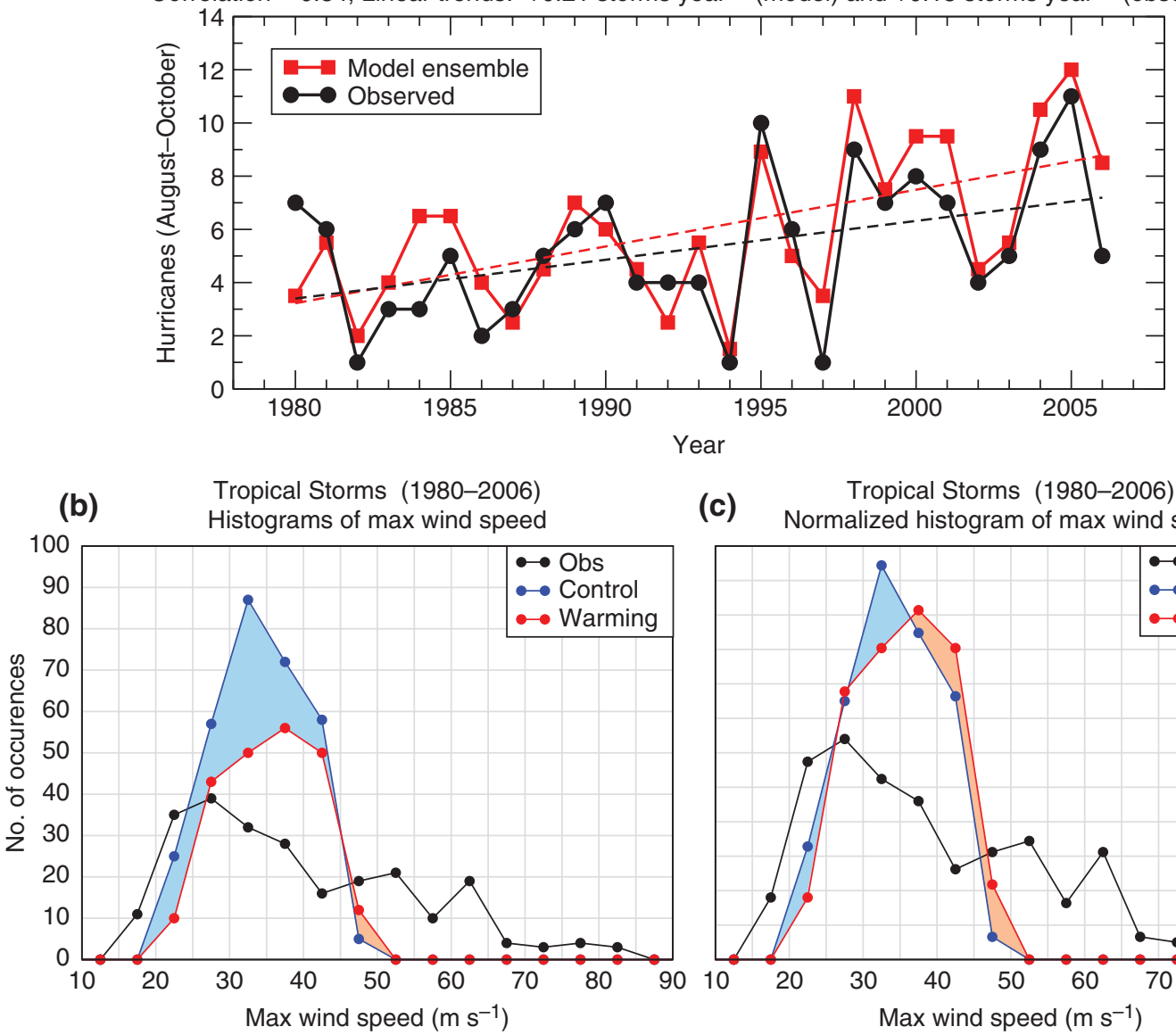

(c)

Tropical Storms (1980-2006)

Normalized histogram of max wind speed

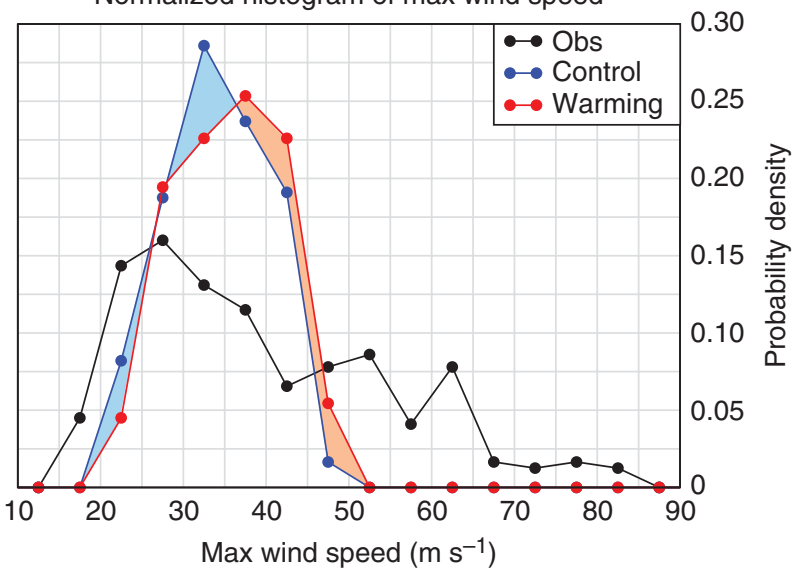

FIGURE 5 | Model versus observed Atlantic hurricane counts and distributions of maximum tropical cyclone wind speeds. (a) Annual (AugustOctober) counts of Atlantic hurricanes in observations and for the model using observed SSTs and large-scale nudging of the interior solution toward reanalyses. $(b, c)$ Histograms of maximum wind speeds $\mathrm{m} \mathrm{s}^{-1}$ (one value per storm) for each Atlantic storm observed or simulated by the model for the control 1980-2006 (August-October) and global warming cases. The normalized histogram (c) was obtained by dividing the total number of storms observed or simulated during the 27-year period. This controls for differences in storm frequency between experiments or between the control and observations. (Reprinted with permission from Ref 70. Copyright 2008 MacMillan Publishers Ltd: Nature Geoscience)

Wind Scale, Bender et al. ${ }^{58}$ performed a second level of downscaling and used the operational GFDL hurricane forecast model to the simulate storms from the regional model. With this method, a realistic distribution of the most intense storms for the current climate was obtained. They found that, by the end of the 21 st century, the frequency of Category 4 and 5 storms in the Atlantic is expected to double (Figure 6). Recently, Knutson et al. ${ }^{74}$ extended this approach to the globe; first, a GFDL high-resolution atmospheric model is used to generate TCs globally, then, each of the individual TCs is re-simulated with the GFDL hurricane coupled model. The results are in agreement with previous studies, with reduced frequency and increased intensity of TCs in the late 21st century.
Done et al. ${ }^{75}$ analyzed the sensitivity of simulated TCs to regional model resolution and noted that although higher resolution is required to resolve the small-scale structural characteristics of the TCs, this level of detail may not be necessary for climate predictions and therefore may be not the optimal use of resources. Furthermore, regional climate simulations can be severely affected by biases in the driving global climate model, even when large domains are employed, so it is important to correct for these biases.

An alternative method for downscaling TC activity from climate models was developed by Emanuel. $^{76,77}$ This technique involves generating a very large number of synthetic storm tracks with realistic intensity based on model or reanalysis environmental 

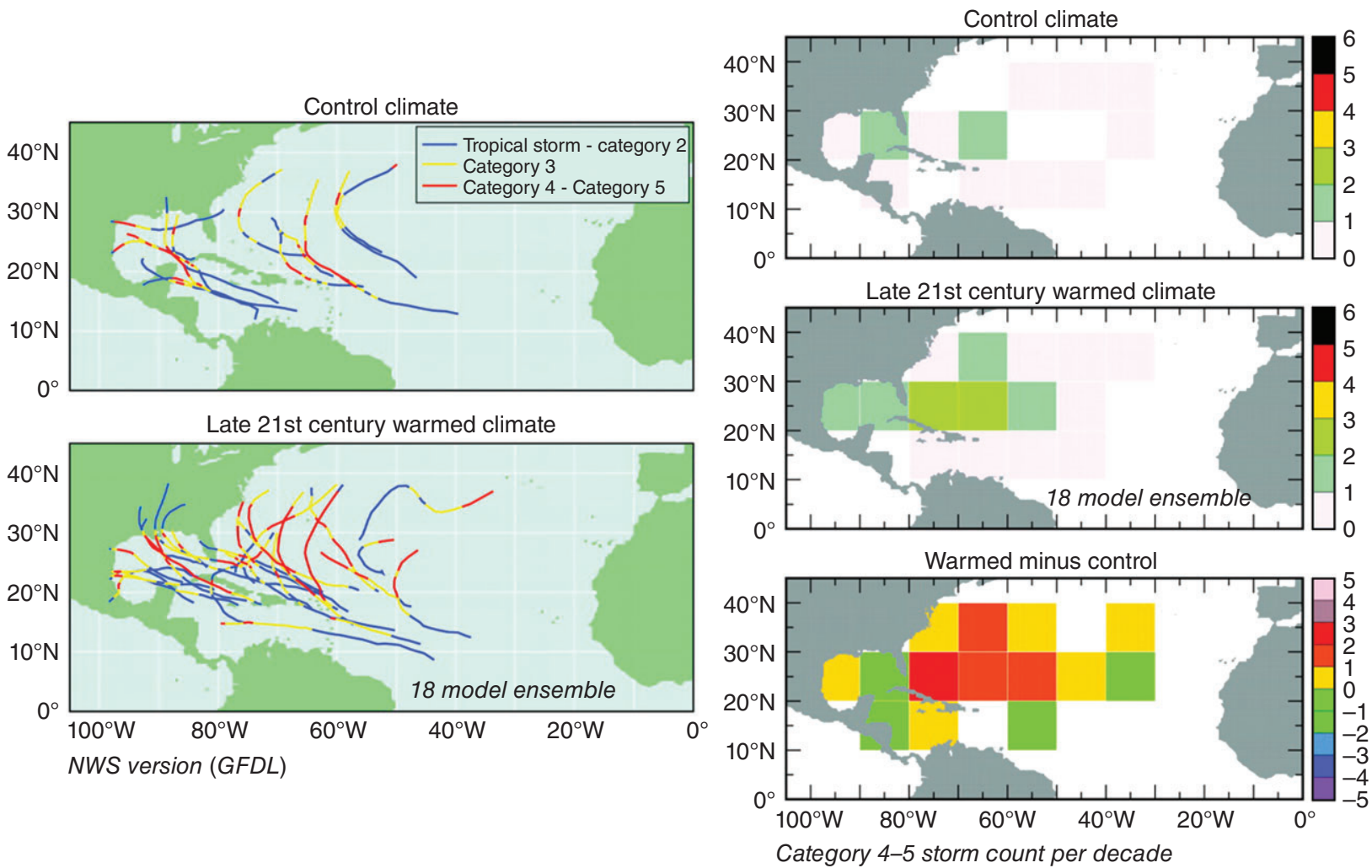

FIG URE 6 | (Left) Tracks for all storms reaching category 4 or 5 intensity, for the control and the warmed 18-model ensemble conditions, as obtained using the GFDL/NWS hurricane model. (Right) the spatial distribution of category 4 and 5 occurrences (scaled by storm counts per decade) for the combined control (average of the GFDL and GFDN model versions, top right); the combined CMIP3 18-model ensemble warmed climate results (middle right); and the difference between the warmed climate and control intense hurricane occurrences (bottom right).

(Reprinted with permission from Ref 58. Copyright 2015 AAAS)

fields and can be a very powerful tool for analyzing TC landfall risk in regions with few landfalling storms in the historical record. ${ }^{78}$ The first step of this technique is to seed storms by a random draw from the space-time probability density function of genesis location obtained from observations. The survival of the seeds depends on the large-scale environmental conditions and the synthetic tracks are then generated for the surviving storms. This technique has been successfully applied to analyze changes in TC characteristics under global warming, using the environmental fields from present and future climates to generate the synthetic TC tracks. Interestingly, different projections for the global TC frequency at the end of the 21st century were obtained when downscaling the $\mathrm{CMIP} 3^{78}$ and $\mathrm{CMIP} 5^{79}$ models. When applied to the CMIP3 models, Emanuel's technique projected a decrease in global TC frequency ${ }^{80}$ (in agreement with most modeling studies), but when applied to the CMIP5 models, Emanuel's technique projected an increase in global TC frequency. ${ }^{81}$ The reason for this discrepancy is not clear, as the largescale fields that are relevant for TC formation and intensification are quite similar between the CMIP3 and CMIP5 models, as was shown by Camargo. ${ }^{39}$

\section{TC DYNAMICAL SEASONAL FORECASTS}

The development of dynamical seasonal forecasts of TCs played an important role in the improvement of the simulation of TCs in climate models. Recent reviews of TC seasonal forecasts (statistical and dynamical) appeared in Vitart ${ }^{82}$ and Camargo et al.; ${ }^{83,84}$ here we only discuss dynamical TC forecasts. As mentioned above, Vitart et al. ${ }^{19,20}$ first showed that the GFDL global climate model was able to reproduce many characteristics of the TC response to ENSO events. A few years later, Vitart and Stockdale ${ }^{85}$ developed the first dynamical seasonal forecast of TCs using ECMWF's coupled 
atmosphere-ocean model system. Even though the predicted mean frequency of storms in the individual basins was significantly lower than observed, the model produced realistic forecasts of interannual variability of TC frequency over the North Atlantic and western North Pacific. They showed that model skill likely results from its ability to predict SSTs; in particular, the occurrence and development of ENSO events and their modulation of TC activity through teleconnections.

The ability of low-resolution models to simulate the modulation of TC activity by ENSO was further explored in a multi-model analysis of models forced with prescribed observed SSTs. ${ }^{86}$ Despite the lowresolution and model biases, these climate models were shown to have significant skill in predicting some properties of TC activity on interannual time scales. This led to the development of the IRI (International Research Institute for Climate and Society) TC seasonal forecasts, which use a twotiered system. First, the SSTs are predicted using various types of dynamic and statistical models, then the atmospheric models are forced with these SSTs and the TCs are tracked in the atmosphere model output. This is in contrast to the ECMWF system, in which a coupled atmospheric-ocean model was utilized. The skill of the IRI seasonal prediction system was shown to be competitive with, and in some circumstances superior to, statistical models. ${ }^{87}$

The success of these early dynamical TC seasonal forecasts led to the development of similar forecasts by various modeling groups ${ }^{88-91}$ including a multi-model forecast system, ${ }^{92,93}$ and hybrid statistical-dynamical systems. ${ }^{94,95}$ An example of a dynamical seasonal forecast of Atlantic TCs, using a multi-model ensemble, is shown in Figure 7. Most importantly, modeling groups across the globe have started to analyze the TC activity in their climate models routinely, which could potentially lead to significant improvement in the representation of TCs in climate models.

Currently, various modeling groups issue dynamical TC seasonal forecasts in various basins with significant skill. The skill can be particularly high in the Atlantic basin, due the strong modulation of TC activity in that basin by ENSO. The current challenge is to develop skillful forecasts from climate models for quantities more relevant to the society than basin-wide frequency or accumulated cyclone energy (ACE, sum of the square of the maximum wind speed of the storms in a basin at all times for which the speed is at least $35 \mathrm{kt}$ ). For instance, skillful forecasts of the probability of occurrence of landfalling storms for specific coastal regions would be a

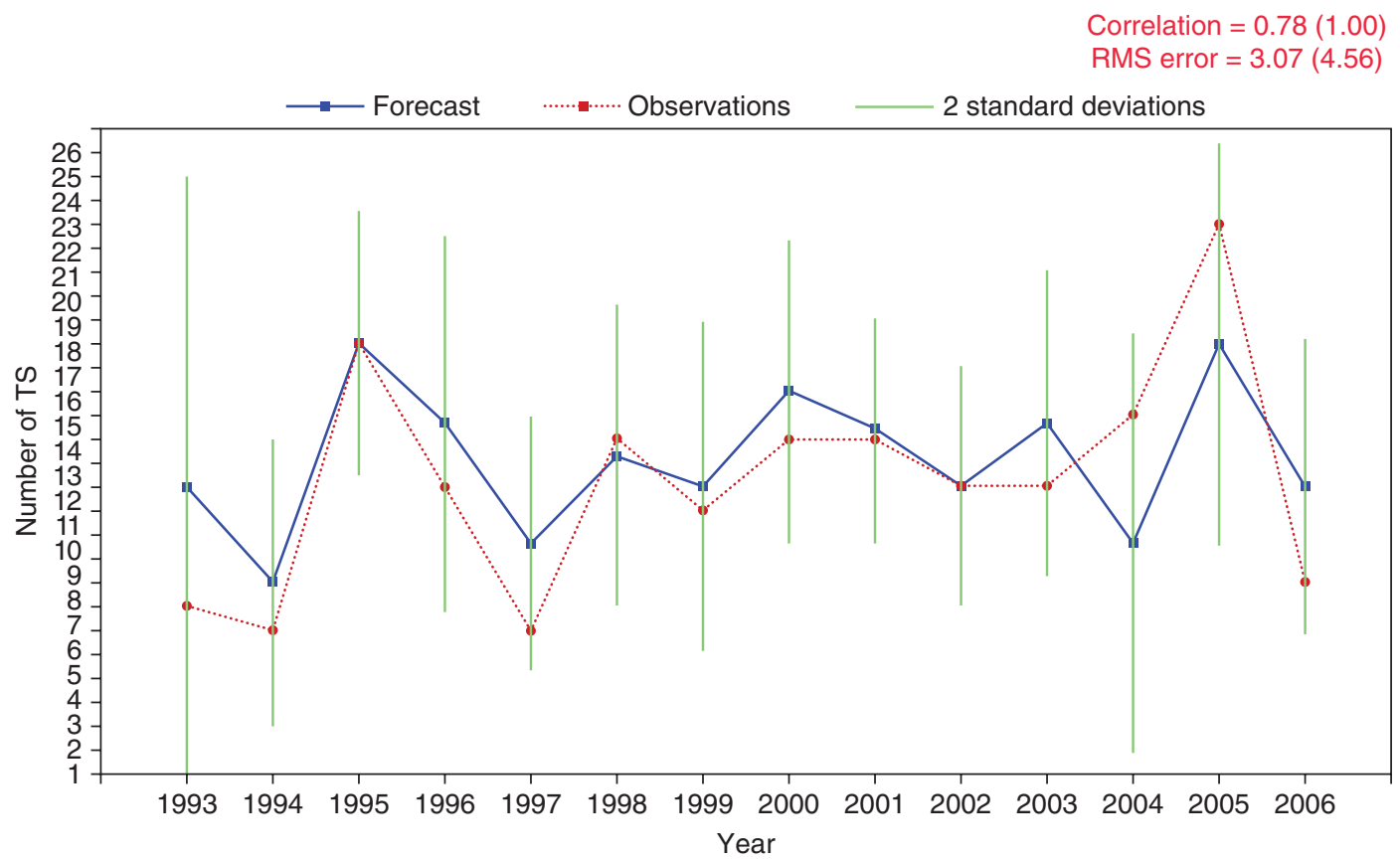

FIGURE 7 | Number of North Atlantic tropical storms from July to November predicted by EUROSIP (median) starting on June 1 (thick black line) for the period 1993-2006. Retrospective forecasts were used for the period 1993-2004, and real-time forecast ensembles (calibrated using the median) were used for the period 2005-2006. The dashed gray line represents observations from July to November and the vertical lines represent two standard deviations within the multi-model ensemble distribution. (Adapted from Ref 93 with permission. Copyright 2007 American Geophysical Union. Made available under the Creative Commons Attribution (CC-BY) License) 
huge improvement from basin-wide quantities. In coupled models, the simulation of the TC-ENSO relationship can be more challenging, as the model can have biases in the representation of the ENSO itself, as well as biases in the environmental response to ENSO. ${ }^{96}$ Recent work using a coupled oceanatmospheric model with flux adjustment to correct systematic ocean biases has produced skillful forecasts of seasonal TC activity on spatial scales finer than basin-wide months in advance of the TC season. ${ }^{97}$ This is a significant progress toward more societally relevant TC seasonal forecasts.

\section{CURRENT STATE-OF-THE-ART GLOBAL CLIMATE MODELS: FROM INTRASEASONAL TO DECADAL TIME SCALES}

In the last few years, there has been a significant increase in the number of modeling groups investing resources in studying TC activity in global climate models. Currently, most modeling groups perform analyses of TC activity as a routine part of their model diagnostics. Although most of the resources have been concentrated on long-time scales, in particular, on the question on how climate change will affect TC activity, many groups have been exploring their model skill on other time scales, from intraseasonal to decadal. We have already discussed (in TC DYNAMICAL SEASONAL FORECASTS) the current ability of climate models to simulate TC activity on seasonal time scales. In this section, we focus on the status of TC prediction on intraseasonal and decadal time scales.

The Madden-Julian Oscillation (MJO, Madden and Julian ${ }^{98-100}$ ) is the main source of predictability in the tropics on intraseasonal time scales. The MJO modulates TC activity globally; ${ }^{101-103}$ when the $\mathrm{MJO}$ is in the enhanced convective or active phase in a certain region, there is a tendency for a higher TC formation in that region. As the MJO propagates eastward, the preferred region for TC genesis also shifts eastward. The modulation of TCs by the MJO in various regions is well established in the literature. ${ }^{104-108}$ TC frequency is not the only property affected by the MJO; others, such as the rate of occurrence of a specific track type, ${ }^{109-111}$ the percentage of storms which reach major hurricane intensity, ${ }^{112}$ and even the response of TCs to ENSO $^{113}$ are as well.

Until recently, the representation of the MJO in climate models was quite poor. ${ }^{114}$ The quality of the MJO simulation in climate models can be improved by modifying the cumulus parameterization used in the models. However, these modifications usually create other biases in the climate models, and therefore are not routinely implemented. ${ }^{115}$ Because of the difficulty in simulating the MJO, the simulation of the modulation of TCs by the MJO has been quite challenging. Only recently a few modeling groups have been able to successfully simulate the TC-MJO relationship. The first such simulation was performed with the Japanese high-resolution cloud-resolving model NICAM (Nonhydrostatic ICosahedral Atmospheric Model), which simulated one MJO event and its link to TC genesis in the western North Pacific. ${ }^{116}$ The ECMWF modeling system uses a seamless prediction approach, in which the same model is used for predicting time scales ranging from synoptic to decadal. ${ }^{117}$ This system has been shown to have skill in simulating the evolution of the MJO and teleconnections of the MJO that are consistent with observations. ${ }^{118,119}$ The ECMWF system simulates the modulation of TC activity by the MJO quite well, even in the northern hemisphere TC season, when the MJO signal is weaker ${ }^{120}$ (Figure 8). The performance of the ECMWF system in real time for the 2008 and 2009 seasons showed that the ECMWF ensemble provided good guidance on TC formation and tracks on time scales of $10-30$ days. ${ }^{122,123}$ The ECMWF ensemble was also able to predict the formation of nearly all the TCs in the 2009 and 2010 seasons, missing only a small number of storms (which were generally short lived and weak ${ }^{124}$ ). The performance of the model over the Atlantic has a somewhat lower skill, though, ${ }^{125}$ and an analysis of the model predictability showed that the model skill is sensitive to the phase and intensity of the MJO and the time of the model initialization. ${ }^{126}$ A comparison of the performance of the ECMWF forecast system with a statistical model ${ }^{127}$ for weekly TC activity in the southern hemisphere showed that the dynamical model had a better performance than the statistical model in the first 2 weeks of the forecast. ${ }^{128}$

More recently, other modeling groups have been making progress in simulating the MJO modulation of TC activity. It has been shown that the GFDL HiRAM (High-Resolution Atmospheric Model) global climate model is able to reproduce the MJO-TC relationship in the eastern North Pacific. ${ }^{129}$ Furthermore, the HiRAM model forecasts on intraseasonal times scales for the North Atlantic are showing promising results. ${ }^{130,131}$ A comparison of two very high-resolution global climate models for a period of eight boreal summers showed how sensitive TC genesis is to the characteristics of the MJO (formation, propagation, and strength), and that the 


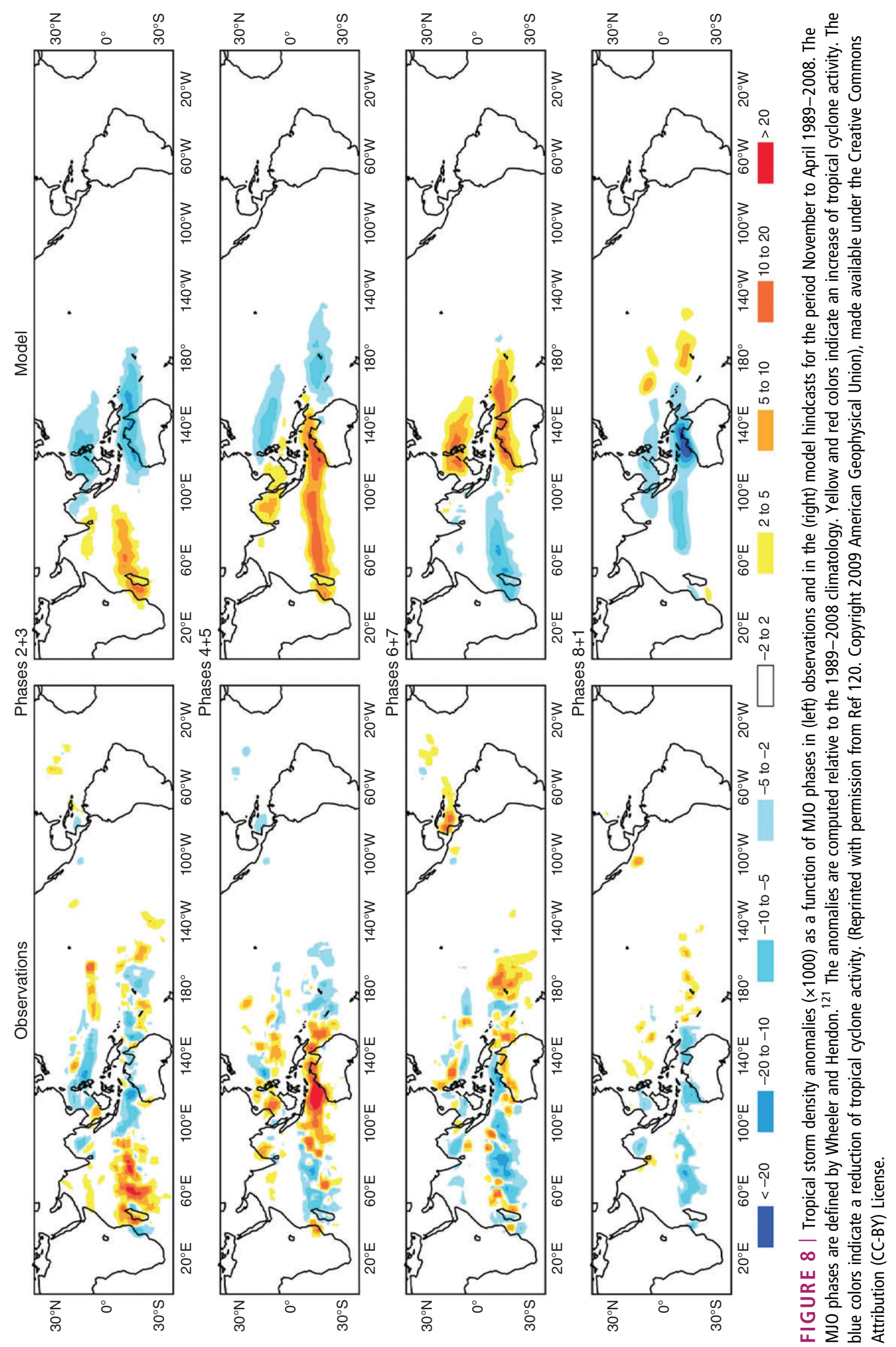


TC-MJO modulation is highly model dependent, ${ }^{132}$ as was also seen in simulations of the MJO and TC genesis during the DYNAMO field program in the North Indian Ocean. ${ }^{133}$ In the case of the GEOS-5 (Goddard Earth Observing System Model, version 5) model, even though the model MJO is faster and weaker than the observed MJO, the model is still able to reproduce the observed MJO-TC modulation. ${ }^{134}$ Intraseasonal forecasts of TC activity are a very promising area for future work, in particular, the seamless prediction approach, in which the same models are used for both weather and climate prediction.

Decadal prediction focuses on predictions over the 10- to 30-year timeframe, and is a bridge between seasonal predictions and climate-change projections. In the last few years, a significant effort has been made by the climate community in this area. ${ }^{135-137}$ While skillful seasonal predictions depend on an accurate specification on the current state of the climate, initial conditions do not influence climate change projections. On decadal time scales, however, the climate is strongly influenced by both natural variability and external forcing, so both accurate initial conditions and anthropogenic greenhouse gas aerosol forcing $^{138}$ are necessary. Early work on hindcast experiments using initialized coupled models showed promise in decadal predictions, ${ }^{139,140}$ which has been confirmed in more recent studies. ${ }^{141,142}$

The decadal variability of TC activity has been discussed in various basins, in particular the North Atlantic $^{143}$ and the western North Pacific. ${ }^{144}$ In the Atlantic, the existence of a natural mode of the decadal variability, the Atlantic Multidecadal Variability (AMV, also referred to in the literature as the Atlantic Multidecadal Oscillation) has been challenged by the argument that the fluctuations were instead caused by a combination of external forcing, including greenhouse gases and industrial and volcanic aerosols. ${ }^{145,146}$ Recently, Caron et al. ${ }^{147}$ noted that the influence of seasonal climate modes on Atlantic TC activity was dependent on the phase of the AMV. In the western North Pacific, the decadal variability in typhoon activity has been associated with the Pacific Decadal Oscillation. ${ }^{144}$

Smith et al. explored the possibility of issuing multi-year forecasts of TC activity in the North Atlantic. ${ }^{148}$ They showed that their decadal prediction system had some skill in predicting 5-year mean North Atlantic TC frequency. Another study, using a different model, found the forecasted 5-year mean showed significant correlation when compared with the null hypothesis of a zero correlation. ${ }^{149}$ They pointed out, though, that the model skill arises in large part from the persistence of the SST in the initialized forecasts (Figure 9), rather than due to the prediction of the system evolution per se. This has been debated in the literature. ${ }^{153,154}$ More recently, Caron et al. ${ }^{155}$ showed that multi-year prediction of Atlantic hurricane activity by CMIP5 models in hindcast mode had modest positive skill, even after accounting for persistence in the climate shift that occurred in 1994-1995. The potential for predicting possible wind damage related to hurricanes along the U.S. coast using a multi-model ensemble of initialized global climate models has also been recently demonstrated. ${ }^{156}$ Decadal predictability of TC activity is a new field and it is expected that more modeling groups will explore this topic in the next few years.

\section{CURRENT STATE-OF-THE-ART GLOBAL CLIMATE MODELS: CLIMATE CHANGE PROJECTIONS}

In the last few years, a large effort has been made toward understanding and making projections of TC activity under climate change. This effort was in large part responsible for a significant progress in simulating TCs in global climate models. In this section, we focus on the studies that analyze TC activity directly from global climate models; we have already discussed the analysis of model large-scale environmental quantities and downscaling studies in Large-scale Environment and TCs and Regional climate models, downscaling and TCs, respectively. A comprehensive review of various aspects (theoretical, modeling, observed trends, attribution) of the relationship between climate change and TCs can be found in Knutson et al., ${ }^{23}$ with an update in Walsh et al. ${ }^{157}$ Here, we focus only on the studies of TCs under climate change using global climate models.

Most of the effort toward the improvement of the simulation of TCs in climate models has been directed at the use of high-resolution global climate models, instead of low-resolution ones. Even in the latest round of simulations for the IPCC (CMIP5), most coupled model simulations were still performed with low-resolution and still have significant biases in reproducing TC climatology. ${ }^{39}$ In order to achieve robust projections from climate model simulations, it is necessary to perform the simulations for many years, using large ensembles and multiple scenarios. Therefore, for most modeling groups it remains very expensive to run coupled models for this purpose. The most common approach is to use atmospheric only models, forced with SSTs (or SST anomalies) obtained from low-resolution coupled simulations. 

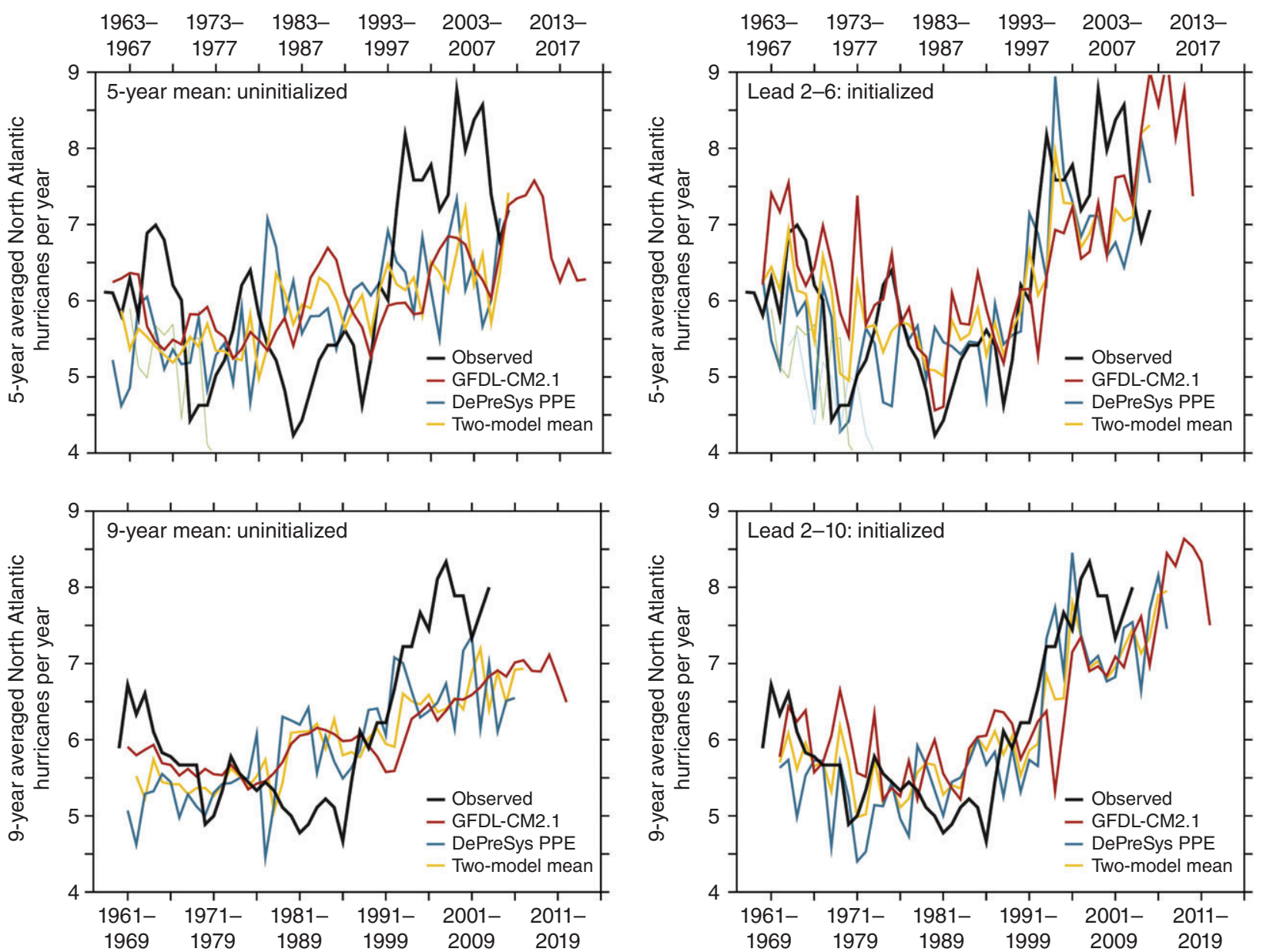

FIGURE 9 | Retrospective and future forecasts of hurricane frequency: (top) retrospective forecasts for 5-year-running hurricane frequency and (bottom) 9-year-running forecasts, showing results from (left) uninitialized and (right) initialized experiments. Black lines show the observed 5- and 9-year hurricane counts from the NOAA Hurricane Database (HURDAT; Jarvinen et al., 1984, ${ }^{150}$ McAdie et al., $2009^{151}$ ), which includes an adjustment for observing inhomogeneity prior to 1966 described in Vecchi and Knutson (2011). ${ }^{152}$ For the retrospective forecasts, the red line shows the forecasts from the GFDL CM2.1 (coupled model version 2.1) system, the blue line shows the UKMO-DePreSys PPE System (United Kingdom MetOffice decadal prediction system), and the yellow line shows the two-system ensemble mean. (Reprinted with permission from Ref 149. Copyright 2013 American Meteorological Society)

The earlier studies to use this approach used (approximately $125 \mathrm{~km}$ ) horizontal resolution models in the late $1990 \mathrm{~s}^{5}$ and early $2000 \mathrm{~s}^{157}$ This method is employed by most of the studies published in the last few years. ${ }^{158-161}$ An example of global TC tracks in both the current and future climate from one of these high-resolution simulations ${ }^{159}$ is shown in Figure 10. While the TC climatology, structure, and intensity are substantially improved by using high horizontal resolution, it is well known that the future projections are very sensitive to the specific SST anomaly patterns used, ${ }^{158}$ and in particular, regional TC changes are very sensitive to different warming patterns. ${ }^{162}$ Therefore, it is essential to have a better understanding of the mechanisms for tropical SST changes. ${ }^{163}$
Another important question regards the direct contribution of $\mathrm{CO}_{2}$ to future changes in TC activity. Inspired by idealized experiments initially designed by Yoshimura and Sugi ${ }^{164}$ and Held and Zhao, ${ }^{165}$ the U.S. CLIVAR Hurricane Working Group (HWG) designed idealized experiments in which highresolution atmospheric climate models were forced with climatological SSTs (present climate or a homogeneous SST increase of $2 \mathrm{~K}$ ) and different levels of $\mathrm{CO}_{2}$ concentration (current values or doubled concentration), as described in detail in Walsh et al. ${ }^{166}$ The main objective of the HWG was to obtain a better understanding of the relationship between climate forcings and TC occurrence using a multi-model approach. A few models of the HWG produce a decrease rather than in an increase in the number of 
(a)

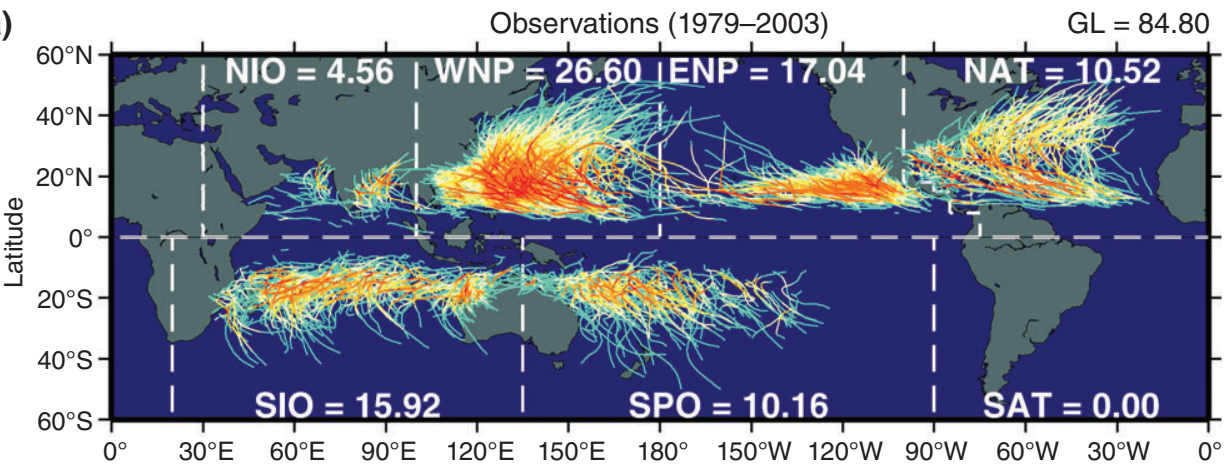

(b)

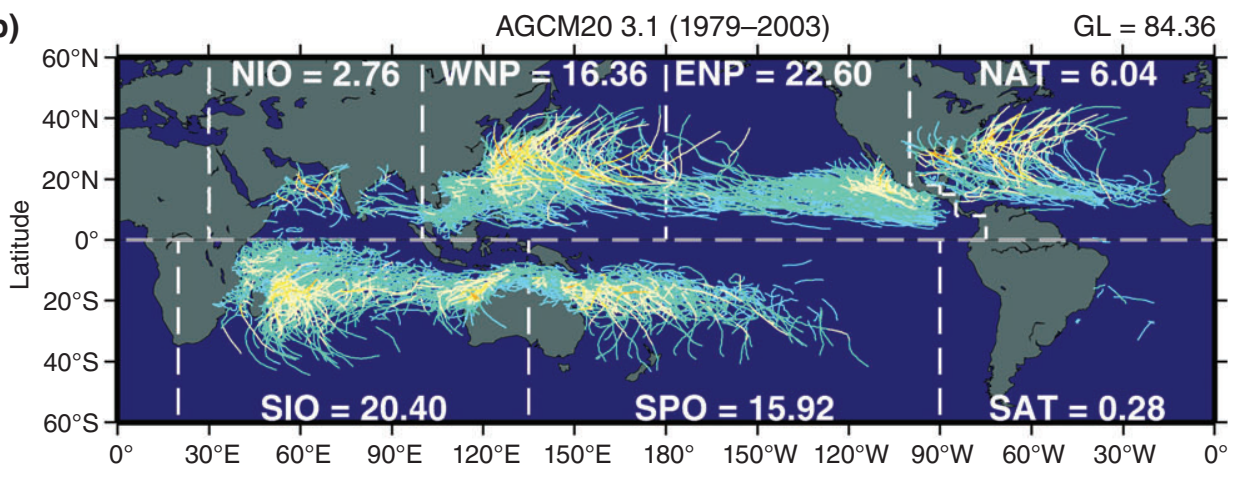

(c) AGCM20 3.2 (1979-2003)

$\mathrm{GL}=84.68$

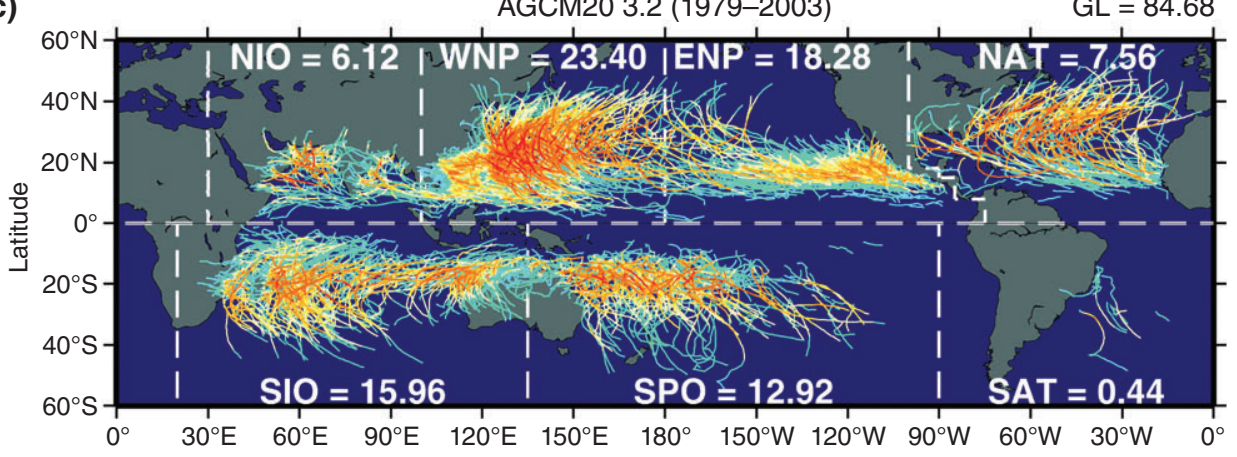

(d)

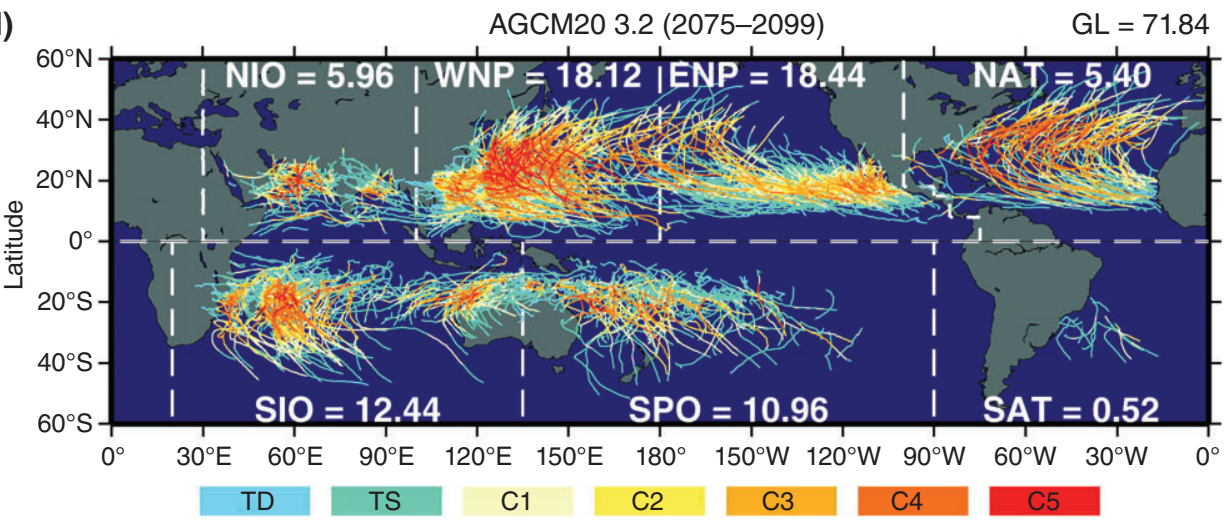

FIGURE 10 | Global distribution of TC tracks during all seasons from 1979 to 2003 for (a) observations, (b) the PD simulation using AGCM20_3.1-Meteorological Research Institute (MRI) atmospheric general circulation model (AGCM) version 3.1, (c) the PD (present day) simulation using AGCM20_3.2 (MRI AGCM version 3.2), and (d) the GW projection using AGCM20_3.2. The numbers for each basin show the annual mean number of TCs. TC tracks are colored according to the intensities of the TCs as categorized by the Saffir-Simpson hurricane wind scale [e.g., tropical depression (TD), tropical storms (TSs), and Categories C1-C5]. (Reprinted with permission from Ref 159. Copyright 2012 American Meteorological Society) 
TCs with a homogeneous $2 \mathrm{~K}$ increase in SST, while most models show a decrease in TC occurrence when forced with a doubled $\mathrm{CO}_{2}$ concentration and no change in SSTs. Detailed analysis of the results of these idealized experiments, including many aspects of the response of TC activity to climate forcings, can be found in numerous papers from the HWG. ${ }^{167-172}$

Given the existing issues with high-resolution climate models forced with fixed SST, especially the sensitivity of TC activity to the details of SST patterns and lack of oceanic feedback on the TCs, a few studies in the last several years have used highresolution coupled ocean-atmospheric models. Gualdi et al. ${ }^{173}$ found that global TC frequency was reduced in a climate change coupled model simulation, similar to the results from models forced with fixed SSTs and other more recent coupled model studies. ${ }^{174,175}$ A similar experiment with the GFDL coupled model and a doubling of $\mathrm{CO}_{2}$ confirmed these results; ${ }^{176}$ there was a substantial reduction in global TC frequency and a small increase in TC intensity globally. In contrast, Bell et al. ${ }^{177}$ only obtained an increase in intensity in their coupled experiments with a quadrupling of $\mathrm{CO}_{2}$. Their timeslice, uncoupled experiments with doubled $\mathrm{CO}_{2}$ with the same atmospheric model; however, did show an increase in TC intensity. Further work is needed to better understand the difference between projections of TC activity under climate change between coupled and uncoupled simulations.

\section{MODEL SENSITIVITIES}

Though there has been a huge improvement in the simulation of TCs in climate models in recent years, there are many issues that still need to be better understood. The model results are sensitive to details both internal and external to the models. In addition to the sensitivity to the SST patterns discussed above, Murakami et al. ${ }^{178}$ showed the importance of taking into account model biases when simulating TCs in climate models by doing bias corrections in their analysis. They showed that by calibrating the models' performance in each basin by the model bias in TC frequency in the present climate, they obtained more reliable projections of TC frequency in the future. Another approach, already mentioned above in $T C$ Dynamical Seasonal Forecasts, is to use a fluxadjusted version of a global climate model in order to improve the simulation of mean climate, leading to improvements in the simulation of TCs and improved regional seasonal forecasts. ${ }^{97}$ Another option, used in seamless weather-to-climate predictions, improves the initial ocean state by modifying the data assimilation algorithm, maintaining interactions between small-scale perturbations and the successively corrected large-scale background. ${ }^{179}$

As mentioned above, an increase in model horizontal resolution is known to lead to a better representation of TCs in models, both for atmospheric models forced with fixed SSTs ${ }^{168,180-183}$ and for coupled models. ${ }^{184}$ However, simply increasing the resolution is not a solution to all the problems in simulating TCs in climate models, as is evident by the different performances of models with similar or the same resolutions. ${ }^{39,167,185}$ Roberts et al. ${ }^{161}$ also showed that while some aspects of TC simulation are indeed improved by using higher resolution (e.g., simulation of TCs in the Atlantic because of a better representation of the easterly waves), others are not improved, such as the weak intensity of simulated TCs. Model resolution also continues to be an issue for very long simulations. The most common approach to solve this problem is to use regional climate models, but as discussed above, there are many unsolved issues with regards to their use, especially related to the domain boundaries and domain size. New numerical techniques, such as variable resolution meshes ${ }^{185,186}$ or the use of a spectral element dynamical core, ${ }^{187-189}$ show some promise of improving models and their ability to simulate smallscale phenomenon like TCs.

The methods used to track TCs in models are another important issue. For instance, in the case of the CMIP5 models, analysis of the TC activity under future climate change has been shown to be dependent on the type of tracking routine, as is evident when comparing the results of two CMIP5 studies. $^{39,190}$ A comparison of tracking schemes applied to the CLIVAR HWG models ${ }^{170}$ showed a moderate agreement between different tracking methods, with some models and experiments showing a better agreement across schemes than others, but there was a dependence on the thresholds used in the tracking routines. ${ }^{191}$ As resolution increases and the models are able to simulate more intense TCs, the difference between tracking algorithms is reduced, as it is easier to identify TCs. However, sensitivity to the detection and tracking algorithm remains an issue for weaker storms, which could influence the resulting TC frequencies. It would be ideal to have a standardized detection and tracking technique to be used across all models.

Nearly all tropical atmospheric phenomena, including TCs, are tightly coupled to clouds and convection and are thus strongly sensitive to the details 
of convective parameterizations. This will likely remain an issue until we are able to run global models with high enough resolution such that convective parameterizations are not necessary. In the current class of climate models, the mean global frequency of TCs is extremely sensitive to the details of the convection scheme. For instance, Kim et al. ${ }^{192}$ implemented small changes to the entrainment rate in the convection scheme in the GISS (Goddard Institute for Space Studies) model (done to improve the MJO simulation), and obtained a very different TC climatology. Vitart et al. ${ }^{193}$ showed that TC frequency, intensity, structure, and interannual variability exhibit significant sensitivities to changes in convective parameterization, in particular, to the production of deep convection. Zhao et al. ${ }^{194}$ identified counterintuitive sensitivities of TC genesis frequency in their model to two parameters in the convection scheme: the horizontal cumulus mixing rate, which controls the entrainment into convective cores, and the strength of the damping of the horizontal flow. They found that as the cumulus mixing rate increases, the model initially has a sharp increase in global TC frequency, followed by decrease, while the TC mean intensity rises monotonically. As the divergence damping strength increases, the model has a continuous increase of the TC frequency, with little change in TC mean intensity. Lim et al. obtained similar results ${ }^{195}$ using another model. One compromise in the interim may be to use super-parameterized models, in which the convective parameterization is replaced by a cloud resolving model that is inserted into each model grid box. Stan ${ }^{196}$ showed a significant improvement in the simulation of Atlantic TCs when using a super-parameterized version of a climate model. However, the convective parameterization is not the only factor that influences the simulation of TCs. Another possible way to assess these model uncertainties is to perform multi-physics experiments, i.e., multiple simulations of the same model with different physics choices, as was done by Murakami et al. ${ }^{197}$

\section{CONCLUSION}

In the last few years, the climate community has put significant effort into improving the simulation of TCs in climate models. The current state-of-the-art global climate models are much better at simulating the TC climatology, interannual variability, and intensity than their predecessors. The improvement has been remarkable and extends from forecasting on multiple time scales from intraseasonal to decadal and should contribute toward more robust projections about TC activity under climate change.

As the ability of the models to simulate the MJO, easterly waves and other equatorial waves improves, so does the skill in forecasting TCs on the 1- to 3-week time scale. ${ }^{123,198,199}$ Beyond that, multiyear TC forecasts have been performed by various groups in the last few years. ${ }^{148,149,155}$ Increased computer power makes the concept of seamless prediction from weather to climate a more realistic objective. ${ }^{200,201}$ Efforts toward seamless prediction are ongoing in various modeling groups, ${ }^{202}$ and this seems to be the best way to incorporate these advances in modeling TCs on shorter time scales to climate models. However, there are still many challenges that need to be addressed, if we want to have more skillful forecasts and robust projections.

On intraseasonal time scales, only a few models are able to simulate a realistic MJO and efforts to improve the MJO simulation can lead to other model biases, ${ }^{203}$ so there are still advances to be made. On seasonal time scales, efforts should be made to move beyond basin-wide forecasts to more societally relevant skillful regional or landfalling forecasts. ${ }^{97}$ On decadal time scales, the big question is how much skill there is in forecasting the SST patterns that are necessary for doing multi-year TC forecasts; this question is being explored for the Atlantic, ${ }^{204}$ the Pacific, ${ }^{205}$ and the decadal variability of ENSO. ${ }^{206}$ Regarding climate change projections, the biggest challenge is to obtain reliable projections of future SST changes including their patterns, and to move beyond global TC projections and toward robust regional changes. Model simulations of paleoclimate TC activity are a new field, with only a few existing studies, ${ }^{47,48,207}$ but could be extremely helpful in shedding light on future TC projections.

Efforts on modeling improvements, from convective parameterizations to new numerical methods and dynamical cores, also need to continue to occur. But most of all, what is needed is a better theoretical understanding of what sets the frequency of TCs. We could make much more confident climate change projections if we had a firmer theoretical expectation of what should happen. Therefore, more basic, fundamental research on the sensitivities and environmental controls of the global climatology of TCs (such as, for example, aquaplanet simulations ${ }^{208}$ and idealized studies of convection self-aggregation and its link to $\mathrm{TCs}^{209,210}$ ) should be encouraged, as part of the effort to improve TC forecasts and climate change projections. Additionally, work on comparing the mechanisms of TC formation in models and to 
that in observations may also give us more confidence in the TC activity simulated by climate models. In summary, despite the recent advances, there is still need for a substantial community effort to improve the simulation of TCs in climate models on all time scales.

\section{ACKNOWLEDGMENTS}

SJC and AAW acknowledge support from the National Science Foundation (NSF, grant AGS-1143959). SJC additionally acknowledges support from the National Oceanic and Atmospheric Administration (NOAA, grant NA110AR4310093). AAW is supported by a NSF AGS Postdoctoral Research Fellowship, under award No. 1433251. We thank two anonymous reviewers for helpful comments on an earlier version of this manuscript.

\section{FURTHER READING}

Knutson TR, Sirutis JJ, Zhao M, Tuleya RE, Bender M, Vecchi GA, Villarini G, Chavas D. Global projections of intense tropical cyclone activity for the late twenty-first century from dynamical downscaling of CMIP5/RCP4.5 scenarios. J Clim 2015, 28:7203-7224.

Walsh KJE, Camargo SJ, Vecchi GA, Daloz AS, Elsner J, Emanuel K, Horn M, Lim Y-K, Roberts M, Patricola C, et al. Hurricanes and climate: the U.S. CLIVAR working group on hurricanes. Bull Am Meteorol Soc 2015, 96:997-1017.

\section{REFERENCES}

1. Manabe S, Holloway JL, Stone HM. Tropical circulation in a time-integration of a global model atmosphere. J Atmos Sci 1970, 27:580-613.

2. Bengtsson L, Böttger H, Kanamitsu M. Simulation of hurricane-type vortices in a general circulation model. Tellus 1982, 34:440-457.

3. Broccoli AJ, Manabe S. Can existing climate models be used to study anthropogenic changes in tropical cyclone climate? Geophys Res Lett 1990, 17:1917-1920.

4. Haarsma RJ, Mitchell JFB, Senior CA. Tropical disturbances in a GCM. Clim Dyn 1993, 8:247-257.

5. Bengtsson L, Botzet M, Esch M. Will greenhouse gasinduced warming over the next 50 years lead to higher frequency and greater intensity of hurricanes? Tellus 1996, 48A:57-73.

6. Dell'Osso L, Bengtsson L. Prediction of a typhoon using a fine-mesh NWP model. Tellus 1985, 37A:97-105.

7. Heckley WA, Miller MJ, Betts AK. An example of hurricane tracking and forecasting with a global analysisforecasting system. Bull Am Meteorol Soc 1987, 68:226-229.

8. Tuleya RE. A numerical study of the genesis of tropical storms observed during the FGGE year. Mon Weather Rev 1987, 115:1188-1208.

9. Krishnamurti TN, Oosterhof D, Dignon N. Hurricane prediction with a high resolution global model. Mon Weather Rev 1989, 117:631-669.
10. Krishnamurti TN, Oosterhof D. Prediction of the life cycle of a supertyphoon with a high-resolution global model. Bull Am Meteorol Soc 1989, 70:1218-1230.

11. Nicholls N. A possible method for predicting seasonal tropical cyclone activity in the Australian region. Mon Weather Rev 1979, 107:1221-1224.

12. Nicholls N. The Southern Oscillation, sea-surface temperature, and interannual fluctuations in Australian tropical cyclone activity. J Climatol 1984, 4:661-670.

13. Nicholls N. Predictability of interannual variations of Australian seasonal tropical cyclone activity. Mon Weather Rev 1985, 113:1144-1149.

14. Gray WM. Atlantic seasonal hurricane frequency. Part I: El-Niño and 30-MB quasi-biennial oscillation influences. Mon Weather Rev 1984, 112:1649-1688.

15. Wu G, Lau NC. A GCM simulation of the relationship between tropical-storm formation and ENSO. Mon Weather Rev 1992, 120:958-977.

16. Broccoli AJ, Manabe S. Reply to Evans. Geophys Res Lett 1992, 19:1525-1526.

17. Bengtsson L, Botzet M, Esch M. Hurricane-type vortices in a general circulation model. Tellus 1995, 47A:175-196.

18. Tsutsui JI, Kasahara A. Simulated tropical cyclones using the National Center for Atmospheric Research community climate model. I Geophys Res 1996, 101:15013-15032.

19. Vitart F, Anderson JL, Stern WF. Simulation of interannual variability of tropical storm frequency in an 
ensemble of GCM integrations. J Clim 1997, 10:745-760.

20. Vitart F, Anderson JL, Stern WF. Impact of large-scale circulation on tropical storm frequency, intensity, and location simulated by an ensemble of GCM integrations. J Clim 1999, 12:3237-3254.

21. Emanuel KA. The dependence of hurricane intensity on climate. Nature 1987, 326:483-485.

22. Emanuel KA. The maximum intensity of hurricanes. J Atmos Sci 1988, 45:1143-1155.

23. Knutson TR, McBride JL, Chan J, Emanuel K, Holland G, Landsea C, Held I, Kossin JP, Srivastava AK, Sugi M. Tropical cyclones and climate change. Nat Geosci 2010, 3:157-163.

24. Camargo SJ, Barnston AG, Zebiak SE. A statistical assessment of tropical cyclone activity in atmospheric general circulation models. Tellus A 2005, 57A:589-604.

25. Camargo SJ, Emanuel KA, Sobel AH. Use of a genesis potential index to diagnose ENSO effects on tropical cyclone genesis. J Clim 2007, 20:4819-4834.

26. Gray WM. Hurricanes: their formation, structure and likely role in the tropical circulation. In: Shaw DB, ed. Meteorology over the Tropical Oceans. Bracknall, UK: Royal Meteorological Society; 1979.

27. Emanuel K, Nolan DS. Tropical cyclone activity and the global climate system. In: Proceedings of 26th AMS Conference on Hurricanes and Tropical Meteorology, No. 10A.2, 2004, 240-241.

28. Emanuel KA. An air-sea interaction theory for tropical cyclones. Part I: steady-state maintenance. J Atmos Sci 1986, 43:585-604.

29. Bister M, Emanuel KA. Low frequency variability of tropical cyclone potential intensity: 1 . Interannual to interdecadal variability. J Geophys Res 2002, 107:4801. doi:10.1029/2001JD000776.

30. Emanuel K. Tropical cyclone activity downscaled from NOAA-CIRES Reanalysis, 1908-1958. J Adv Model Earth Syst 2010, 2:1. doi:10.3894/JAMES.2010.2.1.

31. Tippett MK, Camargo SJ, Sobel AH. A Poisson regression index for tropical cyclone genesis and the role of large-scale vorticity in genesis. J Clim 2011, 24:2335-2357.

32. Bruyère CL, Holland GJ, Towler E. Investigating the use of a genesis potential index for tropical cyclones in the North Atlantic basin. J Clim 2012, 25:8611-8626.

33. Menkes CE, Lengaigne M, Marchesiello P, Jourdain NC, Vincent EM, Lefevre J, Chauvin F, Royer J-F. Comparison of tropical cyclogenesis indices on seasonal to interannual timescales. Clim Dyn 2011, 38:301-321.

34. Ryan BF, Watterson IG, Evans JL. Tropical cyclones frequencies inferred from Gray's yearly genesis parameter: validation of GCM tropical climate. Geophys Res Lett 1992, 19:1831-1834.
35. Watterson IG, Evans JL, Ryan BF. Seasonal and interannual variability of tropical cyclogenesis: diagnostics from large-scale fields. J Clim 1995, 8:3052-3066.

36. Camargo SJ, Sobel AH, Barnston AG, Emanuel KA. Tropical cyclone genesis potential index in climate models. Tellus 2007, 59A:428-443.

37. McDonald RE, Bleaken DG, Cresswell DR, Pope VD, Senior CA. Tropical storms: representation and diagnosis in climate models and the impacts of climate change. Clim Dyn 2005, 25:19-36.

38. Walsh K, Lavender S, Scoccimarro E, Murakami H. Resolution dependence of tropical cyclone formation in CMIP3 and finer resolution models. Clim Dyn 2013, 40:585-599.

39. Camargo SJ. Global and regional aspects of tropical cyclone activity in the CMIP5 models. J Clim 2013, 26:9880-9902.

40. Waters JJ, Evans JL, Forest CE. Large-scale diagnostics of tropical cyclogenesis potential using environment variability metrics and logistic regression models. J Clim 2012, 25:6092-6107.

41. Yokoi S, Takayuba YN. Multi-model projection of global warming impact on tropical cyclone genesis frequency over the western North Pacific. J Meteorol Soc Jpn 2009, 87:525-538.

42. Yokoi S, Takayuba YN. Attribution of decadal variability in tropical cyclone passage frequency over the western North Pacific: a new approach emphasizing the genesis location of cyclones. I Clim 2012, 26:973-987.

43. Emanuel KA. Downscaling CMIP5 climate models shows increased tropical cyclone activity over the 21st century. Proc Natl Acad Sci USA 2013, 110:1221912224. doi:10.1073/pnas.1301293110.

44. Camargo SJ, Tippett MK, Sobel AH, Vecchi GA, Zhao $\mathrm{M}$. Testing the performance of tropical cyclone genesis indices in future climates using the HIRAM model. J Clim 2014, 27:9171-9196.

45. Frappier A, Knutson T, Liu KB, Emanuel K. Perspective: coordinating paleoclimate research on tropical cyclones with hurricane-climate theory and modelling. Tellus 2007, 59A:529-537.

46. Wallace DJ, Woodruff JD, Anderson JB, Donnelly JP. Paleohurricane reconstructions from sedimentary archives along the Gulf of Mexico, Caribbean Sea and western North Atlantic Ocean Margins. Geol Soc Spec Publ 2014, 388:481-501. doi:10.1144/SP388.12.

47. Korty RL, Camargo SJ, Galewsky J. Tropical cyclone genesis factors in simulations of the Last Glacial Maximum. J Clim 2012, 25:4348-4365.

48. Korty RL, Camargo SJ, Galewsky J. Variations in tropical cyclone genesis factors in simulations of the Holocene Epoch. J Clim 2012, 25:8196-8211. 
49. Tang B, Emanuel K. Midlevel ventilation's constraint on tropical cyclone intensity. J Atmos Sci 2010, 67:3354-3360. doi:10.1175/JCLI3799.1.

50. Tang B, Emanuel K. A ventilation index for tropical cyclones. Bull Am Meteorol Soc 2010, 93:1901-1912.

51. Tang B, Camargo SJ. Environmental control of tropical cyclones in CMIP5: a ventilation perspective. $J A d v$ Model Earth Syst 2014, 6:115-128. doi:10.1002/ 2013 MS000294.

52. Wing AA, Sobel AH, Camargo SJ. The relationship between the potential and actual intensities of tropical cyclones on interannual time scales. Geophys Res Lett 2007, 34:L08810.

53. Kossin JP, Camargo SJ. Hurricane track variability and secular potential intensity trends. Clim Change 2009, 9:329-337.

54. Vecchi GA, Soden BJ. Effect of remote sea surface temperature change on tropical cyclone potential intensity. Nature 2007, 450:1066-1070. doi:10.1038/ nature 06423.

55. Camargo SJ, Ting M, Kushnir Y. Influence of local and remote SST on North Atlantic tropical cyclone potential intensity. Clim Dyn 2013, 40:1515-1529.

56. Ting M, Camargo SJ, Li C, Kushnir Y. Natural and forced North Atlantic hurricane potential intensity change in CMIP5 models. J Clim 2015, 28:3926-3942.

57. Polvani LM, Camargo SJ, Garcia RR. The importance of the Montreal Protocol in mitigating the potential intensity of tropical cyclones. J Clim. Submitted for publication.

58. Bender MA, Knutson TR, Tuleya RE, Sirutis JJ, Vecchi GA, Garner ST, Held IM. Modeled impact of anthropogenic warming on the frequency of intense Atlantic hurricanes. Science 2010, 327:454-458.

59. Knutson TR, Tuleya RE, Kurihara Y. Simulated increase of hurricane intensities in a $\mathrm{CO} 2$-warmed climate. Science 1998, 279:1018-1020.

60. Knutson TR, Tuleya RE. Increased hurricane intensities with $\mathrm{CO} 2$ - induced warming on simulated hurricane intensity and precipitation: sensitivity to choice of climate model and convective parameterization. J Clim 2004, 17:3477-3495.

61. Hill KA, Lackmann GM. The impact of future climate change on TC intensity and structure: downscaling approach. J Clim 2011, 24:4644-4661.

62. Knutson TR, Tuleya RE. Increased hurricane intensities with $\mathrm{CO} 2$-induced global warming as simulated using the GFDL hurricane prediction system. Clim Dyn 1999, 15:503-519.

63. Knutson TR, Tuleya RE, Shen W, Ginis I. Impact of $\mathrm{CO}_{2}$-induced warming on hurricane intensities as simulated in a hurricane model with ocean coupling. J Clim 2011, 14:2458-2468.
64. Seth A, Giorgi F. The effects of domain choice in summer precipitation simulation and sensitivity in a regional climate model. J Clim 1998, 11:2698-2712.

65. Landman WA, Seth A, Camargo SJ. The effect of regional climate model domain choice on the simulation of tropical cyclone-like vortices in the Southwestern Indian Ocean. J Clim 2005, 18:1253-1274.

66. Camargo SJ, Li H, Sun L. Feasibility study for downscaling seasonal tropical cyclone activity. Int J Climatol 2007, 27:311-325.

67. Caron LP, Jones CG. Understanding and simulating the link between African easterly waves and Atlantic tropical cyclone using a regional climate model: the role of domain size and lateral boundary conditions. Clim Dyn 2012, 39:113-135.

68. Huang WR, Chan JCL. Dynamical downscaling of western North Pacific tropical cyclone genesis and landfall. Clim Dyn 2014, 42:2227-2237.

69. Knutson TR, Sirutis JJ, Garner ST, Held IM, Tuleya RE. Simulation of the recent multidecadal increase of Atlantic hurricane activity using an 18 -km-grid regional model. Bull Am Meteorol Soc 2007, 88:1549-1565.

70. Knutson TR, Sirutis JJ, Garner ST, Vecchi GA, Held IM. Simulated reduction in Atlantic hurricane frequency under twenty-first-century warming conditions. Nat Geosci 2008, 1:359-364.

71. Knutson TR, Sirutis JJ, Vecchi GA, Garner S, Zhao M, Kim HS, Bender M, Tuleya RE, Held IM, Villarini G. Dynamical downscaling projections of twenty-firstcentury Atlantic hurricane activity: CMIP3 and CMIP5 model-based scenarios. J Clim 2013, 26:6591-6617.

72. Stowasser M, Wang Y, Hamilton K. Tropical cyclone changes in the western North Pacific in a global warming scenario. J Clim 2007, 20:2378-2396.

73. Wu L, Chou C, Chen CT, Huang RH, Knutson TR, Sirutis JJ, Garner ST, Kerr C, Lee CJ, Chien YC. Simulations of the present and late-twenty-first-century Western North Pacific tropical cyclone activity using a regional model. J Clim 2014, 9:3405-3424.

74. Knutson TR, Sirutis JJ, Zhao M, Tuleya RE, Bender M, Vecchi GA, Villarini G, Chavas D. Global projections of intense tropical cyclone activity for the late twenty-first century from dynamical downscaling of CMIP5/RCP4.5 scenarios. J Clim 2015, 28:7203-7224.

75. Done JM, Holland GJ, Bruyère CL, Leung LR, SuzukiParker A. Modeling high-impact weather and climate: lessons from a tropical cyclone perspective. Clim Change 2015, 129:381-395.

76. Emanuel K. Climate and tropical cyclone activity: a new model downscaling approach. J Clim 2006, 19:4797-4802. 
77. Emanuel K, Ravela S, Vivant E, Risi C. A statistical deterministic approach to hurricane risk assessment. Bull Am Meteorol Soc 2006, 87:299-314.

78. Meehl GA, Covey C, Delworth T, Latif M, McAvaney B, Mitchell JFB, Stouffer RJ, Taylor KE. The WRCP CMIP3 multimodel dataset: a new era in climate change research. Bull Am Meteorol Soc 2007, 88:1383-1394.

79. Taylor KE, Stouffer RJ, Meehl GA. An overview of CMIP5 and the experiment design. Bull Am Meteorol Soc 2012, 93:485-498.

80. Emanuel K, Sundararajan R, Williams J. Hurricanes and global warming: results from downscaling IPCC AR4 simulations. Bull Am Meteorol Soc 2008, 89:347-367.

81. Emanuel KA. Downscaling CMIP5 climate models shows increased tropical cyclone activity over the 21st century. Proc Natl Acad Sci USA 2013, 110:1221912224.

82. Vitart F. Seasonal forecasts. In: Proceedings of 8th International Workshop on Tropical Cyclones, Jeju, Korea, 2-10 December, 2014.

83. Camargo SJ, Barnston AG, Klotzbach PJ, Landsea C. Seasonal tropical cyclone forecasts. WMO Bull 2007, 56:297-309.

84. Camargo SJ, Sobel AH, Barnston AG, Klotzbach PJ. Chapter 11: the influence of natural climate variability, and seasonal forecasts of tropical cyclone activity. In: Chan JCL, Kepert JD, eds. Global Perspectives on Tropical Cyclones, from Science to Mitigation, vol. 4. 2nd ed. Singapore: World Scientific Series on Earth System Science in Asia; 2010, 325-360. ISBN: 978-981-4293-47-1.

85. Vitart FD, Stockdale TN. Seasonal forecasting of tropical storms using coupled GCM integrations. Mon Weather Rev 2001, 129:2521-2537.

86. Camargo SJ, Barnston AG, Zebiak SE. A statistical assessment of tropical cyclone activity in atmospheric general circulation models. Tellus 2015, 57A:589-604.

87. Camargo SJ, Barnston AG. Experimental seasonal dynamical forecasts of tropical cyclone activity at IRI. Weather Forecast 2009, 24:472-491.

88. LaRow TE, Lim YK, Shin DW, Chassignet EP, Cocke S. Atlantic basin seasonal hurricane simulations. J Clim 2008, 21:3191-3206.

89. LaRow TE, Stefanova L, Shin DW, Cocke S. Seasonal Atlantic tropical cyclone hindcasting/forecasting using two sea surface temperature datasets. Geophys Res Lett 2010, 37:L02804.

90. Zhao M, Held IM, Vecchi GA. Retrospective forecasts of the hurricane season using a global atmospheric model assuming persistence of SST anomalies. Mon Weather Rev 2010, 138:3858-3868.
91. Chen JH, Lin SJ. Seasonal predictions of tropical cyclones using a $25-\mathrm{km}$ general circulation model. J Clim 2013, 26:380-398.

92. Vitart F. Seasonal forecasting of tropical storm frequency using a multi-model ensemble. Q J R Meteorol Soc 2006, 132:647-666.

93. Vitart F, Huddleston MR, Déqué M, Peake D, Palmer TN, Stockdale TN, Davey MK, Inenson S, Weisheimer A. Dynamically-based seasonal forecasts of Atlantic tropical storm activity issued in June by EUROSIP. Geophys Res Lett 2007, 34:L16815.

94. Vecchi GA, Zhao M, Wang H, Villarini G, Rosati A, Kumar A, Held IM, Gudgel R. Dynamical predictions of seasonal North Atlantic hurricane activity. Mon Weather Rev 2011, 139:1070-1082.

95. Wang H, Schemm JK, Kumar A, Wang W, Long L, Chelliah M, Bell GD, Peng P. Statistical forecast model for Atlantic seasonal hurricane activity based on the NCEP dynamical seasonal forecast. J Clim 2009, 22:4481-4500.

96. Shaman J, Maloney ED. Shortcomings in climate model simulations of the ENSO-Atlantic hurricane teleconnection. Clim Dyn 2012, 38:1973-1988.

97. Vecchi GA, Delworth T, Gudgel R, Kapnick S, Rosati A, Wittenberg AT, Zeng F, Anderson W, Balaji V, Dixon K, et al. On the seasonal forecasting of regional tropical cyclone activity. J Clim 2014, 27:7994-8016.

98. Madden RA, Julian PR. Description of global circulation cells in the tropics with a 40-45 day period. J Atmos Sci 1972, 29:1109-1123.

99. Madden RA, Julian PR. Observations of the 40-50-day tropical oscillation - a review. Mon Weather Rev 1994, 122:814-837.

100. Zhang C. Madden-Julian oscillation. Rev Geophys 2005, 43:RG2003. doi:10.1029/2004RG000158.

101. Camargo SJ, Wheeler MC, Sobel AH. Diagnosis of the MJO modulation of tropical cyclogenesis using an empirical index. J Atmos Sci 2009, 66:3061-3074.

102. Klotzbach PJ. The Madden-Julian Oscillation's impacts on worldwide tropical cyclone activity. J Clim 2014, 27:2317-2330.

103. Klotzbach PJ, Oliver ECJ. Variations in global tropical cyclone activity and the Madden-Julian Oscillation since the mid-twentieth century. Geophys Res Lett 2015, 42:4199-4207.

104. Nakazawa T. Tropical super clusters within intraseasonal variations over the western Pacific. J Meteorol Soc Jpn 1998, 64:17-34.

105. Liebmann B, Hendon HH, Glick JD. The relationship between tropical cyclones of the western Pacific and Indian oceans and the Madden-Julian oscillation. J Meteorol Soc Jpn 1994, 72:401-411. 
106. Maloney ED, Hartmann DL. Modulation of eastern Pacific hurricanes by the Madden-Julian oscillation. J Clim 2000, 13:1451-1460.

107. Maloney ED, Hartmann DL. Modulation of hurricane activity in the Gulf of Mexico by the MaddenJulian oscillation. Science 2000, 287:2002-2004.

108. Bessafi M, Wheeler MC. Modulation of South Indian Ocean tropical cyclones by the Madden-Julian oscillation and convectively coupled equatorial waves. Mon Weather Rev 2006, 134:638-656.

109. Camargo SJ, Robertson AW, Gaffney SJ, Smyth P, Ghil M. Cluster analysis of typhoon tracks: Part II: large-scale circulation and ENSO. J Clim 2007, 20:3654-3676.

110. Camargo SJ, Robertson AW, Barnston AG, Ghil M. Clustering of eastern North Pacific tropical cyclone tracks: ENSO and MJO effects. Geochem Geophys Geosys 2008, 9:Q06V05. doi:10.1029/ 2007GC001861.

111. Kossin JP, Camargo SJ, Sitkowski M. Climate modulation of North Atlantic hurricane tracks. J Clim 2010, 23:3057-3076.

112. Klotzbach PJ. On the Madden Julian OscillationAtlantic hurricane relationship. J Clim 2010, 23:282-293.

113. Li RCY, Zhou W, Chan JCL. Asymmetric modulation of western North Pacific cyclogenesis by the Madden-Julian Oscillation under ENSO conditions. J Clim 2012, 25:5374-5385.

114. Kim D, Sperber K, Stern W, Waliser D, Kang I-S, Maloney E, Wang W, Weickmann K, Benedict J, Khairoutdinov M, et al. Application of MJO simulation diagnostics to climate models. J Clim 2009, 22:6413-6436.

115. Kim D, Sobel AH, Maloney ED, Frierson DMW, Kang I-S. A systematic relationship between intraseasonal variability and mean state bias in AGCM simulations. J Clim 2011, 24:5506-5520.

116. Oouchi K, Noda AT, Satoh M, Miura H, Tomita H, Nasumo T, Iga S-I. A simulated preconditioning of typhoon genesis controlled by a boreal summer Madden-Julian Oscillation event in a global cloudsystem-resolving model. SOLA 2009, 5:65-68.

117. Bechtold P, Kohler M, Jung T, Doblas-Reyes F, Leutbecher M, Rodwell MJ, Vitart F, Balsamo G. Advances in simulating atmospheric variability with the ECMWF model: from synoptic to decadal time-scales. Q J R Meteorol Soc 2008, 134:1337-1351.

118. Vitart F, Molteni F. Simulation of the Madden-Julian Oscillation and its teleconnections in the ECMWF forecast system. Q J R Meteorol Soc 2010, 136:842-855.
119. Vitart F, Jung T. Impact of the Northern Hemisphere extratropics on the skill in predicting the Madden Julian Oscillation. Geophys Res Lett 2010, 37:L23805.

120. Vitart F. Impact of the Madden Julian Oscillation on tropical storms and risk of landfall in the ECMWF forecast system. Geophys Res Lett 2009, 36:L15802.

121. Wheeler MC, Hendon HH. An all-season real-time multivariate MJO index: development of an index for monitoring and prediction. Mon Weather Rev 2004, 132:1917-1932.

122. Elsberry RL, Jordan MS, Vitart F. Predictability of tropical cyclone events on intraseasonal timescales with the ECMWF monthly forecast model. Asia-Pac J Atmos Sci 2010, 46:135-153.

123. Elsberry RL, Jordan MS, Vitart F. Evaluation of the ECMWF 32-day ensemble predictions during the 2009 season of the western North Pacific tropical cyclone events on intraseasonal timescales. Asia-Pac J Atmos Sci 2011, 47:305-318.

124. Tsai H-C, Elsberry RL, Jordan MS, Vitart F. Objective verifications and false alarm analyses of Western North Pacific tropical cyclone event forecasts by the ECMWF 32-day ensemble. Asia-Pac J Atmos Sci 2013, 49:409-420.

125. Elsberry RL, Tsai H-C, Jordan MS. Extended-range forecasts of Atlantic tropical cyclone events during 2012 using the ECMWF 32-day ensemble predictions. Weather Forecast 2014, 29:271-288.

126. Belanger JI, Curry JA, Webster PJ. Predictability of North Atlantic tropical cyclone activity on intraseasonal time scales. Mon Weather Rev 2010, 138:4362-4274.

127. Leroy A, Wheeler MC. Statistical prediction of weekly tropical cyclone activity in the southern hemisphere. Mon Weather Rev 2009, 136:3637-3654.

128. Vitart F, Leroy A, Wheeler MC. A comparison of dynamical and statistical predictions of weekly tropical cyclone activity in the southern hemisphere. Mon Weather Rev 2010, 138:3671-3682.

129. Jiang X, Zhao M, Waliser DE. Modulation of tropical cyclones over the eastern Pacific by the intraseasonal variability simulated in an AGCM. J Clim 2012, 25:6524-6538.

130. Gall JS, Ginis I, Lin S-J, Marchok TP, Chen J-H. Experimental tropical cyclone prediction using the GFDL 25-km-resolution global atmospheric model. Weather Forecast 2011, 26:1008-1019.

131. Chen J-H, Lin S-J. The remarkable predictability of inter-annual variability of Atlantic hurricanes during the past decade. Geophys Res Lett 2011, 38:L11804. doi:10.1029/2011GL047629.

132. Satoh M, Oouchi K, Natsuno $T$, Taniguchi $H$, Yamada Y, Tomita H, Kodama C, Kinter J, Achuthavarier D, Maganello J, et al. The intra-seasonal 
oscillation and its control of tropical cyclones simulated by high-resolution global atmospheric models. Clim Dyn 2012, 39:9-10.

133. Fu XH, Lee J-Y, Hsu P-C, Taniguchi H, Wang B, Wang WQ, Weaver S. Multi-model MJO forecasting during DYNAMO/CINDY period. Clim Dyn 2013, 41:1067-1081.

134. Kim D, Lee M-I, Kim H-M, Schubert SD, Yoo J-H. The modulation of tropical storm activity in the western North Pacific by the Madden-Julian Oscillation in GEOS-5 AGCM experiments. Atmos Sci Lett 2014, $15: 335-341$.

135. Meehl GA, Goddard L, Murphy J, Stouffer RJ, Boer G, Danabasoglu G, Dixon K, Girogetta MA, Greene AM, Hawkins E, et al. Decadal prediction: can it be skillful? Bull Am Meteorol Soc 2009, 90:1467-1485.

136. Goddard L, Hurrell JW, Kirtman BP, Murphy J, Stockdale T, Vera C. Two time scales for the price of one (almost). Bull Am Meteorol Soc 2012, 93:621-629.

137. Meehl GA, Goddard L, Boer G, Burgman R, Branstator G, Cassou C, Corti S, Danabasoglu G, DoblasReyes F, Hawkins E, et al. Decadal climate prediction: an update from the trenches. Bull Am Meteorol Soc 2014, 95:243-267.

138. Cane MA. Climate science: decadal predictions in demand. Nat Geosci 2010, 3:231-232.

139. Keenlyside NS, Latif M, Junglaus J, Kornblueh L, Rockner E. Advancing decadal-scale climate prediction in the North Atlantic sector. Nature 2008, 453:84-88.

140. Smith DM, Cusack S, Colman AW, Folland CK, Harris GR, Murphy JM. Improved surface temperature prediction for the coming decade from a global climate model. Science 2007, 317:796-799.

141. Yang X, Rosati A, Zhang S, Delworth TL, Gudgel RG, Zhang R, Vecchi G, Anderson W, Chang Y-S, Delsole $\mathrm{T}$, et al. A predictable AMO-like pattern in GFDL's fully-coupled ensemble initialization and decadal forecast system. J Clim 2013, 26:650-661.

142. Kim H-M, Ham Y-G, Scaife AA. Improvement of initialized decadal predictions over the North Pacific Ocean by systematic anomaly pattern correction. J Clim 2014, 27:5148-5162.

143. Goldenberg SB, Landsea CW, Mestas-Nuñez AM, Gray WM. The recent increase in Atlantic hurricane activity: causes and implications. Science 2001, 293:474-479.

144. Chan JCL. Decadal variations of intense typhoon occurrence in the western North Pacific. Proc $R$ Soc A 2008, 464:249-272.
145. Mann ME, Emanuel KA. Atlantic hurricane trends linked to climate change. EOS Trans AGU 2006, $87: 233-241$

146. Zhang R, Dewlorth TL, Sutton R, Hodson DLR, Dixon KW, Held IM, Kushnir Y, Marshall J, Ming Y, Msadek R, et al. Have aerosols caused the observed Atlantic Multidecadal variability? I Atmos Sci 2013, 70:1135-1144.

147. Caron L-P, Boudreault M, Bruyère CL. Changes in large-controls of Atlantic tropical cyclone activity with the phases of the Atlantic multi-decadal oscillation. Clim Dyn 2015, 44:1801-1821.

148. Smith DM, Eade R, Dunston NJ, Fereday D, Murphy JM, Pohlmann H, Scaife AA. Skillful multi-year predictions of Atlantic hurricane frequency. Nat Geosci 2010, 3:846-849.

149. Vecchi GA, Msadek R, Anderson W, Chang Y-S, Delworth T, Dixon K, Gudgel R, Rosati A, Stern W, Villarini G, et al. Multi-year predictions of North Atlantic hurricane frequency: promise and limitations. J Clim 2013, 26:5337-5357.

150. Jarvinen BR, Neumann CJ, Davis MAS. A tropical cyclone data tape for the North Atlantic basin, 1886-1983: contents, limitations, and uses. NOAA Technical Memorandum NWS NHC 22, Coral Gables, FL, 1984, 21 pp.

151. McAdie CJ, Landsea CW, Neumann CJ, David JE, Blake ES, Hammer GR. Tropical Cyclones of the North Atlantic Ocean, 1851-2006. Historical Climatology Series Vol 6-2. National Climatic Data Center, Asheville, NC, 2009, 238 pp.

152. Vecchi GA, Knutson TR. Estimating annual numbers of Atlantic hurricanes missing from the HURDAT database (1878-1965) using ship track density. J Clim 2011, 24:1736-1746.

153. Smith DM, Dunston NJ, Eade R, Fereday D, Hermanson L, Murphy JM. Comments on "Multiyear predictions of North Atlantic hurricane frequency: promises and limitations". I Clim 2014, 27:487-489.

154. Vecchi GA, Msadek R, Anderson W, Chang Y-S, Delworth T, Dixon K, Gudgel R, Rosati A, Stern W, Villarini G, et al. Reply to comments on "Multiyear predictions of North Atlantic hurricane frequency: promise and limitations". J Clim 2014, 27:490-492.

155. Caron L-P, Jones CG, Doblas-Reyes F. Multi-year prediction skill of Atlantic hurricane activity in CMIP5 decadal hindcasts. Clim Dyn 2014, 42:2675-2690.

156. Caron L-P, Hermanson L, Doblas-Reyes FJ. Multiannual forecasts of Atlantic U.S. tropical cyclone wind damage potential. Geophys Res Lett 2015, 42:2417-2425

157. Walsh KJE, McBride JL, Klotzbach PJ, Balachandran, Camargo SJ, Holland G, Knutson TR, Kossin J, Lee 
T-C, Sobel A, Sugi M. Tropical cyclones and climate change. WIREs Clim Change. In press.

158. Zhao M, Held IM. TC-permitting GCM simulations of hurricane frequency response to sea surface temperature anomalies projected for the late-twenty-first century. J Clim 2012, 25:2995-3009.

159. Murakami H, Wang YQ, Yoshimura H, Mizuta R, Sugi M, Shindo E, Adachi Y, Yukimoto S, Hosaka M, Kusunoki S, et al. Future changes in tropical cyclone activity projected by the new high-resolution MRI-AGCM. J Clim 2012, 25:3237-3260.

160. Gleixner S, Keenlyside N, Hodges KI, Tseng W-L, Bengtsson L. An inter-hemispheric comparison of tropical storms response to global warming. Clim Dyn 2014, 42:2147-2157.

161. Roberts MJ, Vidale PL, Mizielinksi MS, Demory ME, Schiemann R, Strachan J, Hodges K, Bell R, Camp J. Tropical cyclones in the UPSCALE ensemble of high-resolution global climate models. J Clim 2015, 28:574-596.

162. Sugi M, Murakami H, Yoshimura J. A reduction in global tropical cyclone frequency due to global warming. SOLA 2009, 5:164-167.

163. Xie S-P, Deser C, Vecchi GA, Ma J, Teng H, Wittenberg AT. Global warming pattern formation: sea surface temperature and rainfall. J Clim 2010, 23:966-986.

164. Yoshimura J, Sugi M. Tropical cyclone climatology in a high-resolution AGCM - impacts of SST warming and $\mathrm{CO}_{2}$ increase. SOLA 2005, 1:133-136.

165. Held IM, Zhao M. The response of tropical cyclone statistics to an increase in $\mathrm{CO}_{2}$ with fixed sea surface temperatures. J Clim 2011, 24:5353-5364.

166. Walsh KJE, Camargo SJ, Vecchi GA, Daloz AS, Elsner J, Emanuel K, Horn M, Lim Y-K, Roberts M, Patricola C, et al. Hurricanes and climate: the U.S. CLIVAR working group on hurricanes. Bull Am Meteorol Soc 2015, 96:997-1017.

167. Shaevitz DA, Camargo SJ, Sobel AH, Jonas JA, Kim D, Kumar A, LaRow TE, Lim Y-K, Murakami $\mathrm{H}$, Reed K, et al. Characteristics of tropical cyclones in high-resolution models of the present climate. J Adv Model Earth Syst 2014, 6:1154-1172.

168. Wehner M, Prabhat, Reed KA, Stone D, Collins WD, Bacmeister J. Resolution dependence on future tropical cyclone projections of CAM5.1 in the U.S. CLIVAR Hurricane Working Group idealized configurations. J Clim 2015, 28:3905-3925.

169. Daloz AS, Camargo SJ, Kossin JP, Emanuel K, Horn M, Jonas JA, Kim D, LaRow T, Lim Y-K, Patricola $\mathrm{CM}$, et al. Cluster analysis of explicitly and downscaled simulated North Atlantic tropical cyclone tracks. J Clim 2015, 28:1333-1361.
170. Horn M, Walsh K, Zhao M, Camargo SJ, Scoccimarro E, Murakami $\mathrm{H}$, Wang $\mathrm{H}$, Ballinger $\mathrm{A}$, Kumar A, Shaevitz DA, et al. Tracking scheme dependence of simulated tropical cyclone response to idealized climate simulations. J Clim 2014, 27:9197-9213.

171. Scoccimarro E, Gualdi S, Villarini G, Vecchi GA, Zhao M, Walsh K, Navarra A. Increased precipitation events associated with landfalling tropical cyclones in response to a warmer climate and increased $\mathrm{CO}_{2}$. J Clim 2014, 27:4642-4654.

172. Villarini G, Lavers DA, Scoccimarro E, Zhao M, Wehner MF, Vecchi GA, Knutson TR, Reed KA. Sensitivity of tropical cyclone rainfall to idealized global scale forcings. J Clim 2014, 27:4622-4641.

173. Gualdi S, Scoccimarro E, Navarra A. Changes in tropical cyclone activity due to global warming: results from a high-resolution coupled general circulation model. J Clim 2008, 21:5204-5228.

174. Scoccimarro E, Gualdi S, Bellucci A, Sanna A, Fogli PG, Manzini E, Vichi M, Oddo P, Navarra A. Effects of tropical cyclones on ocean heat transport in a high resolution coupled general circulation model. I Clim 2011, 24:4368-4384.

175. Rathmann NM, Yang S, Kaas E. Tropical cyclones in enhanced resolution CMIP5 experiments. Clim Dyn 2014, 42:665-681.

176. Kim H-S, Vecchi GA, Knutson TR, Anderson WG, Delworth TL, Rosati A, Zeng F, Zhao M. Tropical cyclone simulation and response to $\mathrm{CO} 2$ doubling in the GFDL CM2.5 high-resolution coupled climate model. J Clim 2014, 27:8034-8054.

177. Bell R, Strachan J, Vidale PL, Hodges K, Roberts M. Response of tropical cyclones to idealized climate change experiments in a global high resolution coupled general circulation model. J Clim 2013, 20:7966-7988.

178. Murakami H, Hsu P-C, Arakawa O, Li T. Influence of model biases on projected future changes in tropical cyclone frequency of occurrence. J Clim 2014, 27:2159-2181.

179. Zhang S, Zhao M, Lin S-J, Yang X, Anderson W. Retrieval of tropical cyclone statistics with a highresolution coupled model and data. Geophys Res Lett 2014, 41:652-660.

180. Manganello JV, Hodges KI, Kinter JL, Cash BA, Marx T, Jung T, Achuthavarier D, Adams JM, Altschuler EL, Huang B, et al. Tropical cyclone climatology in a $10-\mathrm{km}$ global atmospheric GCM: toward weather-resolving climate modeling. J Clim 2012, 25:3867-3893.

181. Strachan J, Vidale PL, Hodges K, Roberts M, Demory M-E. Investigating global tropical cyclone activity with a hierarchy of AGCMs: the role of model resolution. J Clim 2013, 26:133-152. 
182. Walsh K, Lavender S, Scoccimarro E, Murakami H. Resolution dependence of tropical cyclone formation in CMIP3 and finer resolution models. Clim Dyn 2013, 40:585-599.

183. Manganello JV, Hodges KI, Dirtmeyer B, Kinter JL, Cash BA, Marx L, Jung T, Achuthavarier D, Adams JM, Altshuler EL, et al. Future changes in the western North Pacific tropical cyclone activity projected by a multidecadal simulation with a $16-\mathrm{km}$ global atmospheric GCM. J Clim 2014, 27:7622-7646.

184. Murakami H, Vecchi GA, Underwood S, Delworth T, Wittenberg AT, Anderson W, Chen J-H, Gudgel R, Harris L, Lin S-J, et al. Simulation and prediction of category 4 and 5 hurricanes in the high-resolution GFDL HiFLOR coupled climate model. I Clim. In press. doi:10.1175/JCLI-D-15-0216.1.

185. Zarzycki CM, Jablonowski C, Taylor MA. Using variable resolution meshes to model tropical cyclones in the community atmosphere model. Mon Weather Rev 2014, 142:1221-1239.

186. Zarzycki CM, Jablonowski C. A multidecadal simulation of Atlantic tropical cyclones using a variableresolution global atmospheric general circulation. J Adv Model Earth Syst 2014, 6:805-828.

187. Reed KA, Jablonowski C. Assessing the Uncertainty of Tropical Cyclone Simulations in NCAR's Community Atmosphere Model. J Adv Model Earth Syst 2011, 3:M08002 16 pp. doi:10.1029/ 2011MS000076.

188. Reed KA, Jablonowski C, Taylor MA. Tropical cyclones in the spectral element configuration of the Community Atmosphere Model. Atmos Sci Lett 2012, 13:303-310. doi:10.1002/asl.399.

189. Reed KA, Jablonowski C. Idealized tropical cyclone simulations of intermediate complexity: A test case for AGCMs. J Adv Model Earth Syst 2012, 4: M04001. doi:10.1029/2011MS000099.

190. Tory K, Chand SS, McBride JL, Ye H, Dare RA. Projected changes in late 21 st century tropical cyclone frequency in thirteen coupled climate models from the Coupled Model Intercomparison Project Phase 5. J Clim 2013, 26:9946-9959.

191. Walsh KJ, Fiorino M, Landsea CW, McInnes KL. Objectively determined resolution-dependent threshold criteria for the detection of tropical cyclones in climate model and reanalyses. J Clim 2007, 20:2307-2314

192. Kim D, Sobel AH, Del Genio AD, Chen Y, Camargo SJ, Yao M-S, Kelley M, Nazarenko L. The tropical subseasonal variability simulated in the NASA GISS general circulation model. J Clim 2012, 25:4641-4659.

193. Vitart F, Anderson JL, Sirutis J, Tuleya RE. Sensitivity of tropical storms simulated by a general circulation model to changes in cumulus parameterization. Q J R Meteorol Soc 2001, 127:25-51.

194. Zhao M, Held IM, Lin S-J. Some counterintuitive dependencies of tropical cyclone frequency on parameters in a GCM. J Atmos Sci 2012, 69:2272-2283.

195. Lim Y-K, Schubert SD, Reale O, Lee M-I, Molod AM, Suarez MJ. Sensitivity of tropical cyclones to parameterized convection in the NASA GEOS-5 model. J Clim 2015, 28:551-573.

196. Stan C. Is cumulus convection the concertmaster of tropical cyclone activity in the Atlantic? Geophys Res Lett 2012, 39:L19716.

197. Murakami H, Mizuta R, Shindo E. Future changes in tropical cyclone activity project by multiphysics and multi-SST ensemble experiments using 60-km-mesh MRI-AGCM. Clim Dyn 2012, 39:2569-2584.

198. Xiang BQ, Lin S-J, Zhao M, Zhang SQ, Vecchi G, Li T, Jian X-N, Harris L, Chen J-H. Beyond weather time-scale prediction for Hurricane Sandy and SuperTyphoon Haiyan in a global climate model. Mon Weather Rev 2015, 143:524-535.

199. Belanger JI, Webster PJ, Curry JA, Jelinek MT. Extended prediction of North Indian ocean tropical cyclones. Weather Forecast 2012, 27:757-769.

200. Palmer TN, Doblas-Reyes FJ, Weisheimer A, Rodwell MJ. Towards seamless prediction: calibration of climate change projections using seasonal forecasts. Bull Am Meteorol Soc 2008, 89:459-470.

201. Palmer TN. Towards the probabilistic Earth-system simulator: a vision for the future of climate and weather prediction. Q J R Meteorol Soc 2014, 138:841-861. doi:10.1002/qj.1923.

202. Halezeger W, Severijns C, Semmler T, Ştefănescu S, Wang X, Wyser K, Dutra E, Baldasano JM, Bintanja $\mathrm{R}$, Bougeault P, et al. EC-Earth: a seamless earthsystem prediction approach in action. Bull Am Meteorol Soc 2010, 91:1357-1363. doi:10.1175/ 2010BAMS2877.1.

203. Kim D, Sobel AH, Maloney ED, Frierson DMW, Kang I-S. A systematic relationship between intraseasonal variability and mean state bias in AGCM simulations. J Clim 2011, 24:5506-5520.

204. Msadek R, Delworth TL, Rosati A, Anderson W, Vecchi G, Chang Y-S, Dixon K, Gurgel RG, Stern W, Wittenberg A, et al. Predicting a decadal shift in North Atlantic climate variability using the GFDL forecast system. J Clim 2014, 27:6472-6496. doi:10.1175/JCLI-D-13-00476.1.

205. Mochizuki T, Ishii M, Kimoto M, Chikamoto Y, Watanabe M, Nozawa T, Sakamoto TT, Shiogama H, Awaji T, Sugiura N, et al. Pacific decadal oscillation hindcasts relevant to near-term climate prediction. Proc Natl Acad Sci USA 2010, 107:1833-1837. doi:10.1073/pnas.0906531107. 
206. Wittenberg AT, Rosati A, Delworth TL, Vecchi GA, Zeng F. ENSO Modulation: is it decadally predictable? J Clim 2014, 27:2667-2681.

207. Fedorov AV, Brierley CB, Emanuel K. Tropical cyclones and permanent El Niño in the early Pliocene epoch. Nature 2010, 463:1066-1070.

208. Ballinger AP, Merlis TM, Held IM, Zhao M. The sensitivity of tropical cyclone activity to offequatorial thermal forcing in aquaplanet simulations.
J Atmos Sci 2015, 72:2286-2302. doi:10.1175/JASD-14-0284.1.

209. Wing AA, Cronin TW. Self-aggregation of convection in long channel geometry. Q $J R$ Meteorol Soc. In press. doi:10.1002/qj.2628.

210. Khairoutdinov MF, Emanuel K. Rotating radiativeconvective equilibrium simulated by a cloudresolving model. J Adv Model Earth Syst 2013, 5:816-825. 